Discussion papers of the

Max Planck Institute for

Research on Collective Goods

Bonn 2019/7

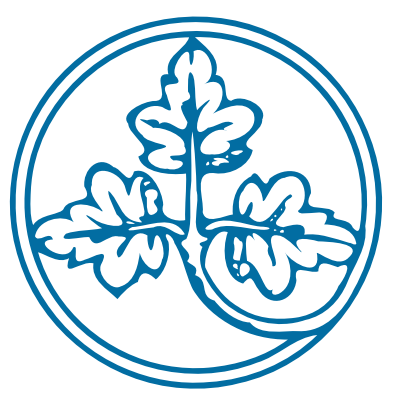

Social Status and Risk-Taking in Investment Decisions

Florian Lindner

Michael Kirchler

Stephanie Rosenkranz

Utz Weitzel

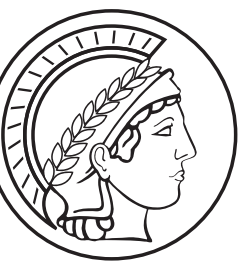




\section{Social Status and Risk-Taking in Investment Decisions}

Florian Lindner / Michael Kirchler / Stephanie Rosenkranz / UtzWeitzel

May 2019 


\title{
Social Status and Risk-Taking in Investment Decisions*
}

\author{
Florian Lindner, Michael Kirchler, Stephanie Rosenkranz, Utz Weitzel ${ }^{\dagger}$
}

May 1, 2019

\begin{abstract}
A pervasive feature in the finance industry is relative performance, which can include extrinsic (money), intrinsic (self-image), and reputational (status) motives. In this paper, we model a portfolio decision with two assets and investigate how reputational motives (i.e., the public announcement of the winners or losers) influence risk-taking in investment decisions vis-a-vis intrinsic motives. We test our hypotheses experimentally with 864 students and 330 financial professionals. We find that reputational motives play a minor role among financial professionals, as the risk-taking of underperformers is already increased due to intrinsic motives. Student behavior, however, is mainly driven by reputational motives with risk-taking levels that come close to those of professionals when winners or losers are announced publicly. This indicates that professionals show higher levels of intrinsic (self-image) incentives to outperform others compared to non-professionals (students), but a similar behavior can be sparked among the latter by adding reputational incentives.
\end{abstract}

JEL: G02, G11, D03, C93

Keywords: experimental finance, behavioral economics, investment game, rank incentives, social status, reputational motives.

\footnotetext{
*We thank participants at the Experimental Finance Conference 2018 in Heidelberg, Economic Science Association meetings 2017 in Vienna and 2018 in Berlin, the MBEES 2018 in Maastricht, as well as seminar participants in St. Gallen, Utrecht, Florence (EUI), and Obergurgl for very valuable comments. We particularly thank all financial institutions and participating professionals for the excellent collaboration and their enthusiasm. Financial support from the Austrian Science Fund (FWF START-grant Y617-G11 and SFB F63), Radboud University, and the Swedish Research Council (grant 2015-01713) is gratefully acknowledged. This study was ethically approved by the IRB of the University of Innsbruck.

${ }^{\dagger}$ Lindner: Max Planck Institute for Research on Collective Goods, Kurt-Schumacher-Str. 10, 53113 Bonn. Email: florian.r.lindner@gmail.com. Kirchler: University of Innsbruck, Department of Banking and Finance, Universitätsstrasse 15, 6020 Innsbruck, and University of Gothenburg, Department of Economics, Centre for Finance, Vasagatan 1, 40530 Gothenburg. Phone: +43 512507 73014, E-mail: michael.kirchler@uibk.ac.at. Rosenkranz: Utrecht University School of Economics, Kriekenpitplein 21-22, 3584 EC Utrecht, E-mail: s.rosenkranz@uu.nl. Weitzel (corresponding author): Utrecht University School of Economics, Kriekenpitplein 21-22, 3584 EC Utrecht, E-mail: u.weitzel@uu.nl; Radboud University, Institute for Management Research, Heyendaalseweg 141, 6525 AJ Nijmegen. E-mail: u.weitzel@fm.ru.nl.
} 


\section{Introduction}

Recent research identified tournament incentives as an important driver for excessive risktaking in finance (Rajan, 2006; Diamond and Rajan, 2009; Bebchuk and Spamann, 2010). In particular, tournament incentives can be characterized by three major components. The first and most obvious component is the extrinsic incentive of money, which often depends on relative performance. Bonuses, for example, which are widespread in the finance industry (Goetzmann et al., 2003), represent extrinsic monetary incentives for outperforming others. The second and third components can be subsumed under rank incentives and address the intrinsic motives of positive self-image (Bénabou and Tirole, 2006; Köszegi, 2006) and reputational motives of improved public status among peers (Frank, 1985; Moldovanu et al., 2007). Rank incentives reflect an evolutionary established pattern to do better than peers and promise a non-monetary utility to those at the top and a disutility to those at the bottom (Barankay, 2015). In line with this, recent experimental evidence shows that rank incentives can indeed increase individuals' effort and performance (Azmat and Iriberri, 2010; Blanes-i-Vidal and Nossol, 2011; Tran and Zeckhauser, 2012; Bandiera et al., 2013; Delfgaauw et al., 2013; Charness et al., 2014; Barankay, 2015).

In the finance industry, performance is very transparent, which makes it relatively easy to establish rankings and to award those that are at the top, both monetarily and with status. Annual awards to top performing fund managers, bankers, and analysts as well as the regular publication of fund rankings (e.g., Morningstar ranking) document a strong culture of social competition. ${ }^{1}$ Given the relevance of rankings in the finance industry, as well as a growing research on preferences for social status (see, e.g., Heffetz and Frank (2011) for an excellent overview), there is surprisingly little literature on how social comparison impacts risk-taking in financial decisions. The first insights into professionals' preferences for high rank have recently been provided by Kirchler et al. (2018). In lab and online experiments, the authors report that underperforming financial professionals increase risk-taking when faced with non-incentivized, anonymous rankings. In the same setting, the authors find no rankdriven behavior among students. Importantly, as the rankings were anonymous and private, the authors focused on intrinsic (self-image) motives of social competition.

In this paper, we extend the insights of Kirchler et al. (2018) on rank incentives by separating the effects of intrinsic (self-image) motives and reputational (status) motives on risk-taking. By disentangling these two motives we follow a similar approach as Schram et al. (2018), who separate the effect of social status (resulting from the social ranking of performances) from pure rivalry for resources in a real effort task. We develop a stylized theoretical model and then test the predictions with laboratory experiments. In the model, we analyze a portfolio decision

\footnotetext{
${ }^{1}$ See, e.g., http:/ / www.fmya.com/; http:/ / www.investmentawards.com; http:/ / www.americanbanker.com/best-in-banking/; http://excellence.thomsonreuters.com/award/starmine.
} 
with two assets and investigate how reputational and intrinsic motives for being at the top or the bottom of a peer ranking influence risk-taking. We conjecture that risk-taking is higher when investors are informed about their rank and when top-ranked or bottom-ranked performers are publicly known. Moreover, our model suggests that when investors at the top or bottom of the ranking are publicly known, the risk-taking of highly ranked investors should be lower than that of underperformers. To test the theoretical predictions we use the experimental design of Kirchler et al. (2018) and analyze the reputational motive by announcing the winner or the loser of a group of six investors publicly at the end of the experiment. This is public knowledge from the start of the experiment. We compare this treatment with a setting where only intrinsic motives can play a role, by displaying anonymous rankings privately and without any public announcement. This comparison is complemented with baseline treatments without any rankings and, consequently, also without any public announcements. Finally, to obtain a comprehensive picture, we test our hypotheses both with 864 non-professional subjects (students) and with 330 financial professionals from investment-related areas (e.g., fund management, trading, private banking, and asset management). ${ }^{2}$

Our results show that, first, average risk-taking among students is higher in treatments in which the winner or the loser is announced publicly, compared to the baseline treatment. Second, we show that the public announcement of the winner or loser increases average risktaking among students compared to a treatment with anonymous rank information. For professionals, however, we do not observe such effects. This indicates that reputational motives can play a role as an additional incentive, but primarily among non-professionals and less so among professionals. Finally, we observe that underperforming investors take more risk than outperformers in treatments where rankings are displayed and the winner or loser is publicly announced. This result holds for both students and professionals. However, while underperforming students do not increase risk-taking without reputation motives, underperforming professionals increase risk-taking primarily due to intrinsic motives and are less concerned about reputation motives. Given professionals' industry experience, reputational motives can be (partly) internalized, which may explain why professionals react relatively strongly based on intrinsic motives.

Kirchler et al. (2018) have shown that intrinsic motivation through anonymous ranking promotes rank-driven risk-taking among underperforming professionals but not among students. Our study implies that reputational motives can spark rank-driven behavior even among nonprofessionals, leading to substantially increased risk-taking among underperforming students. This indicates that when the full scope of motives of social comparison is addressed, i.e., intrinsic self-image concerns as well as reputational status concerns, laypeople react similarly to rankings in investment decisions as professionals do.

\footnotetext{
${ }^{2}$ The baseline and ranking treatments are directly taken from Kirchler et al. (2018) for both students and professionals. This study adds the public announcement of winners and losers to isolate status effects.
} 
The remainder of the paper is organized as follows. In Section 2, we present a simple model of portfolio choice that incorporates non-monetary incentives and allows us to derive hypotheses for our experiment. In Section 3 we introduce the experimental design and implementation. In Section 4 we present the results of the experiment. In Section 5 we discuss our results and conclude the paper.

\section{Theoretical Framework}

In the following we present a simple, stylized model that helps us to derive predictions regarding the effects of intrinsic self-image concerns as well as reputational status concerns on risk-taking. ${ }^{3}$ We model a portfolio decision with two assets. Let us denote the expected and actual return of a risk-free asset as $R_{f}$ and the expected return of a risky asset as $R_{m}$, with $R_{m}>R_{f}$. The expected return of the investor's portfolio, $R_{p}$, is a weighted average of the expected return on the two assets, i.e., $R_{p}(b)=b R_{m}+(1-b) R_{f}$. Note that the standard deviation from the portfolio $\sigma_{p}=b \sigma_{m}$.

Suppose that an investor's utility from her portfolio's return $U(\cdot)$ is a function of her valuation for money $v_{y}$ (derived from the portfolio return $R_{p}$ ), her valuation $v_{r}$ for achieving a certain rank $r_{i}\left(R_{p}\right)$, which stems from the investor's self-image and possibly her social image (status). In our specification of the image valuation we follow Bénabou and Tirole (2016): each investor's preference type $v \equiv\left(v_{r}, v_{y}\right) \in \mathbb{R}^{2}$ is drawn independently from a continuous distribution with density $f(v)$ and means $\left(\hat{v_{r}}, \hat{v_{y}}\right)$. Its realization is private information, only known to the investor when she invests and not observable by others. For simplicity, we assume that it depends linearly on observers' posterior expectations of the investor's type $v$, given her rank. In a setting with $n$ investors, an investor $i$ 's portfolio return is ranked at a given rank with probability $G\left(., r_{i}, r_{-i}\right) \geq 0$, where $-i$ refers to all other investors. If the rank is observed, others get a strong signal regarding an investor's type $v$. The factor $x_{k}>0$ with $k=r, s$ measures the visibility or salience of the rank, and its value thus depends on whether the rank will be observed by the investor herself $\left(x_{r}\right)$ and others respectively $\left(x_{s}\right)$, where $x_{k} \in[0,1]$, depending on the treatment. We assume that an investor chooses the share of risky assets $b$ to maximize her utility, which is given as:

$$
U\left(R_{p}(b), b, r_{i}\left(R_{p}(b)\right)\right)=v_{y}\left(R_{p}(b), b\right)+G\left(., r_{i}, r_{-i}\right)\left(x_{r}+x_{s}\right) v_{r}\left(r_{i}\left(R_{p}(b)\right)\right) .
$$

We assume that function $v_{y}(\cdot)$ is twice differentiable, increasing, and strictly concave in $R_{p}$, while the investor's attitude toward risk is captured by the properties of $v_{y}(\cdot)$ with respect to changes in $b$. To keep our stylized model as tractable and intuitive as possible we make

\footnotetext{
${ }^{3}$ As our aim is to predict treatment effects rather than estimates for the strength or size of underlying parameters, we do not present a more complex structural model that includes non-observable parameters.
} 
a number of simplifying assumptions: (i) we consider the portfolio decision in each period $t$ independently; (ii) while the function $v_{r}(\cdot)$ is a discrete function in rank for $r_{i} \in[1, n]$, which itself is a discrete increasing function of $R_{p}$, we assume without much loss of generality that both are also twice differentiable, increasing, and strictly concave in their arguments; (iii) to avoid introducing further parameters, we assume that the effects of self-image and social image on utility are similar in size.

The investor's optimization problem can thus be written as:

$$
\max _{b}\left(U\left(R_{p}(b), b, r_{i}\left(R_{p}(b)\right)\right) .\right.
$$

Taking the derivative and rearranging the first order condition such that the marginal utility from the investor's valuation for money $v_{y}$ derived from the portfolio return $R_{p}$ is on the righthand side and her marginal reputational benefits $v_{r}$ for achieving a certain rank $r\left(R_{p}\right)$ are on the left-hand side, the optimal portfolio, $b^{*}$, satisfies:

$\alpha\left(G(\cdot) \frac{\partial v_{r}\left(r_{i}\left(R_{p}(b)\right)\right)}{\partial r_{i}} \frac{\left.\partial r_{i}\left(R_{p}(b)\right)\right)}{\partial R_{p}} \frac{\partial R_{p}(b)}{\partial b}+g(\cdot) v_{r}(\cdot)\right)=-\left(\frac{\partial v_{y}\left(R_{p}, b\right)}{\partial R_{p}} \frac{\partial R_{p}(b)}{\partial b}+\frac{\partial v_{y}\left(R_{p}, b\right)}{\partial b}\right)$,

with $\alpha=\left(x_{r}+x_{s}\right)$ and $g(\cdot)$ denoting the derivative of $G\left(., r_{i}, r_{-i}\right) .{ }^{5}$ If the investor's rank is not visible to herself or to others, i.e., $x_{r}=x_{s}=0 \Rightarrow \alpha=0$, the investor's attitude toward risk will determine whether she will buy stocks on the margin or not. For a risk-neutral or riskseeking investor, characterized by $\partial v_{y}\left(R_{p}, b\right) / \partial b \geq 0$, the right-hand side of (3) will be zero or negative, respectively. Thus, the investor's utility increases with a larger $R_{p}$, which leads to a corner solution and therefore the optimal $\tilde{b}^{*}=b_{\max }$, where $\tilde{b}^{*}$ refers to the investor's optimal choice if $x_{r}=x_{s}=0$. In the following, we focus on the more relevant case where the investor is risk averse, i.e., $\partial v_{y}\left(R_{p}, b\right) / \partial b<0$, such that the right-hand side of (3) can be positive, and an inner solution to condition (3) exists.

Now suppose that the investor's rank is visible to herself, i.e., $x_{r}>0 \Rightarrow \alpha>0$. As all factors on the left-hand side of (3) are positive, it is straightforward to note that if the investor's rank is revealed to her, the investor's intrinsic valuation $v_{r}$ for achieving a certain rank $r_{i}\left(R_{p}\right)$ increases risk-taking.

Finally, suppose that the highest (lowest) ranked investor is publicly announced such that the investor's rank is visible to others (and herself) if and only if she is the (highest) lowest ranking investor, i.e., $x_{s}>0 \Rightarrow \alpha>0$. Now status concerns will affect the investor's optimal portfolio decision. As indicated by Bénabou and Tirole (2006), it follows from (3) that observing an investor to be either a winner or a loser reveals the sum of her three motivations (at the margin): intrinsic, extrinsic, and reputational. Heterogeneity in investors' image con-

\footnotetext{
${ }^{4}$ For notational convenience, we thus do not index all variables with $t$.

${ }^{5} \mathrm{We}$ assume that the conditions for the existence of a pure-strategy equilibria are assured.
} 
cerns represents a source of noise that reduces the liability of inferences about $v_{r}$. It is again straightforward to note that if the investor's rank is revealed to others, the investor's intrinsic valuation $v_{r}$ for achieving a rank $r_{i}\left(R_{p}\right)$ increases risk-taking.

We can summarize these insights as follows:

Proposition 1 Suppose the investor is risk averse, i.e., $\partial v_{y}\left(R_{p}, b\right) / \partial b<0$, and intrinsically values a higher rank and status. (i) If the investor's rank is visible to the investor herself, i.e., $x_{r}>0$, the investor's optimal portfolio is characterized by a larger share of the risky asset than when the rank is not visible, i.e., $b^{*}>\tilde{b}^{*}$. (ii) If the investor with the lowest (highest) rank is publicly announced, i.e., $x_{s}>0$, the investor's optimal portfolio is characterized by a larger share of the risky asset than in the absence of the public announcement, i.e., $b^{* *}>\tilde{b}^{*}$. (iii) If the investor's rank is visible to the investor herself and the investor with the lowest (highest) rank is publicly announced, i.e., $x_{r}>0$ and $x_{s}>0$, the investor's optimal portfolio is characterized by a larger share of the risky asset than when the rank is not visible and not publicly announced, i.e., $b^{* * *}>\tilde{b}^{*}$.

Note that investors' extrinsic and reputational motives work in the same direction and increase their marginal utility of taking risk. Whether the announcement of the winner or the announcement of the loser leads investors to hold a larger share of risky assets depends on the relative strength of the extrinsic and reputational motives and can only be determined with stronger assumptions. ${ }^{6}$

Deriving insights regarding the choice of risk depending on an investor's rank in the different scenarios is less straightforward and closely relates to the literature on rank order tournaments with heterogeneous agents. ${ }^{7}$ Expression $G\left(., r_{i}, r_{-i}\right)$ denotes the probability that, given $\mathbf{b}=\left(b_{1}, \ldots, b_{n}\right)$, investor i's portfolio return is ranked at a certain rank. Let us for simplicity consider a situation with only two investors. Then, the probability that a given investor's portfolio return ranks highest will be $1 / 2$ if investors are identical, for example, at the first investment decision. However, if one of the investor's initial returns is higher at the moment of the investment decision (at later stages), then the probability that she is ranked highest will increase in the difference in investors' initial portfolio returns. Gürtler and Kräkel (2010) show for an analogous case that $g(\cdot)$ is symmetric for both investors. ${ }^{8}$ From their analysis we can also conclude that for an investor with larger initial portfolio returns, $G(\cdot)$ is increasing in the

\footnotetext{
${ }^{6}$ Moreover, note that although we do not indicate it explicitly in our notation, when the winner is announced, risk-taking is influenced by the probability to reach the highest rank, while when the loser is announced, risktaking is influenced by the probability to reach any rank that is not the lowest. At the same time, the observers' posterior expectations of the investor's type $v$, given the announcement that the investor is not the loser, is lower than when the investor is announced to be the winner. In general, no clear predictions can be derived from these considerations without stronger assumptions.

${ }^{7}$ See Nieken and Sliwka (2010); Gürtler and Kräkel (2010); Akerlof and Holden (2012); Balafoutas et al. (2017) for tournaments with heterogeneous agents.

${ }^{8}$ Nieken and Sliwka (2010) show for the simplified case of an asymmetric tournament with discrete choice and two agents that a leading player chooses the safe strategy while the lagging player chooses a risky strategy if the difference in the outcome of some prior stage in the competition is sufficiently large and the expected returns are not too different.
} 
initial difference. If we rearrange (3), the following equation shows the effect of an investor's initial portfolio return (expressed in a larger $G(\cdot)$ due to her rank in the previous period) on her optimal level of risk-taking:

$\alpha\left(\frac{\partial v_{r}\left(r_{i}\left(R_{p}(b)\right)\right)}{\partial r_{i}} \frac{\left.\partial r_{i}\left(R_{p}(b)\right)\right)}{\partial R_{p}} \frac{\partial R_{p}(b)}{\partial b}\right)+\frac{g(\cdot)}{G(\cdot)} \alpha v_{r}=-\frac{1}{G(\cdot)}\left(\frac{\partial v_{y}\left(R_{p}, b\right)}{\partial R_{p}} \frac{\partial R_{p}(b)}{\partial b}+\frac{\partial v_{y}\left(R_{p}, b\right)}{\partial b}\right)$.

With larger $G(\cdot)$, both sides of the equation decline. However, if $\alpha$ is sufficiently large, due to the concavity of $v_{r}$ the first term in the brackets on the left-hand side is smaller for an investor with a high initial rank. This implies that for investors with larger initial portfolio returns, the marginal reputational benefits from achieving a certain rank are smaller. Hence, when the rank is visible to the investors themselves, underperformers take more risk than overperformers, as shown in experiments by Kirchler et al. (2018).

In line with these arguments, we thus additionally formulate the following proposition:

Proposition 2 Suppose the investor is risk averse, i.e., $\partial v_{y}\left(R_{p}, b\right) / \partial b<0$ and intrinsically values $a$ higher rank and status. If the rank is visible to the investor herself, i.e., $x_{R}>0$, low ranked investors (underperformers) are holding a larger share of risky assets than highly ranked investors. This is also the case if additionally the rank is visible to others if and only if she is the (highest) lowest ranking investor, i.e., $x_{S}>0$.

\section{Experimental Design and Hypotheses}

\subsection{Design and Treatments}

The subjects played an investment game, which is identical to the design of Kirchler et al. (2018). Over eight periods, the participants repeatedly made portfolio choices between a riskfree alternative and a risky asset. The investment game was inspired by, and resembles games of, Lohrenz et al. (2007), Ehm et al. (2014), Bradbury et al. (2015), and Huber et al. (2016). In each period, the risk-free asset yielded a return of $R_{f}=0.015(1.5 \%)$ and the risky asset paid an expected return of $R_{m}=0.036$ (3.6\%) with a standard deviation of $15.9 \%$. ${ }^{9}$ The participants received information about the mean and standard deviation of the return distribution but no information about the origin of the underlying data (except that they were part of historical financial market data). In each period, the participants decided which fraction $b, R I S K$, of their current portfolio wealth, $W_{p}$, to invest in the risky asset. Portfolio wealth is carried over from one period to the next. The participants were allowed to invest up to $200 \%$ of their portfolio

\footnotetext{
${ }^{9}$ We computed these numbers from time series of the 6-months EURIBOR for the risk-free rate (before 1999: FIBOR, Frankfurt Interbank Offered Rate) and from the DAX 30 for the risky asset. We calculated returns and standard deviations for a 20-year period from January 1, 1994 to December 31, 2013. The numbers reflect semiannual returns and standard deviations.
} 
wealth, meaning that the amount exceeding $W_{p}$ was borrowed at the risk-free rate $R_{f} \cdot{ }^{10}$

We randomly assigned the participants to groups of six, which remained the same for the duration of the investment game. Each group played one of the six treatments in a betweensubjects design. Table A1 outlines the six treatments, based on a $2 \times 3$ design with the treatment variables "Private ranking after each period" and "Public announcement of rank after experiment." The former treatment variable indicates whether an anonymous league table, detailing all group members' current wealth levels, associated rank $(R A N K \in\{1,2, \ldots, 6\})$, and subjects' own position in the ranking, was displayed after each period. This ranking was anonymous and not incentivized. The latter treatment variable indicates whether the top performer (Rank 1), the lowest performer (Rank 6), or nobody at all was publicly announced after the last period. This procedure was common knowledge from the beginning of the experiment. Given that the professional sample was smaller than the student sample, we restricted data collection for the professionals to the four most important treatments to guarantee sufficient statistical power for those treatments. In particular, we did not run treatments with professionals where only the rank after the treatment was publicly announced ("B-WINNER and B-LOSER") .

\section{Table 1: Treatments}

This table outlines the between-subjects $2 \times 3$ treatment design. "Private ranking after each period" indicates whether an anonymous league table, detailing all group members' current wealth levels, associated rank $(R A N K \in$ $\{1,2, \ldots, 6\})$, and subjects' own position in the ranking was displayed after each period. This ranking was not publicly disclosed and not incentivized. "Public announcement of rank after experiment" indicates whether the top performer (Rank 1), the lowest performer (Rank 6), or nobody at all was publicly announced after the last period. Given that the professional sample was smaller than the student sample, we did not run treatments B-WINNER and B-LOSER with professionals.

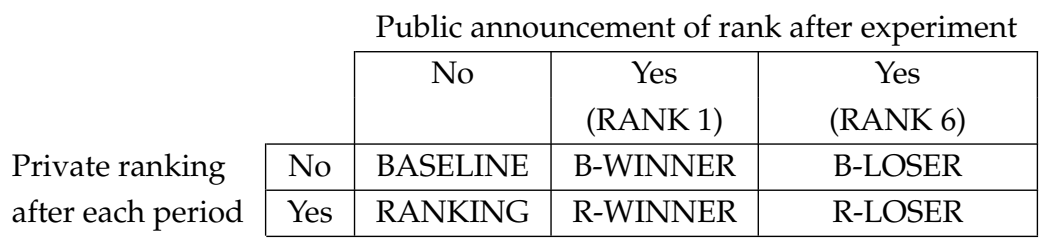

In Treatment BASELINE, the participants faced linear incentives and allocated their portfolio in eight periods without peer feedback. Students received an initial endowment of 30 euro (90 euro for professionals) and accumulated gains and losses depending on their investments over time. In line with Cohn et al. (2014, 2017) and Kirchler et al. (2018), each participant received the payout of the investment game with a probability of $20 \%$ to facilitate high stakes.

\footnotetext{
${ }^{10}$ Before the investment game started, the participants had to sample 30 returns from the theoretical distribution with the above-mentioned first two moments of the distribution. This procedure was intended to increase familiarity with the properties of the risky asset. As Kaufmann et al. (2013) and Bradbury et al. (2015) report, experience sampling increases decision commitment and confidence, while it can also decrease known biases such as overestimation of loss probabilities.
} 
There is a growing body of literature indicating that these commonly used payment schemes with random components do not bias risk-taking behavior in experiments (Starmer and Sugden, 1991; Cubitt et al., 1998; Hey and Lee, 2005; March et al., 2015). Moreover, Charness et al. (2016) pointed out that the pay-one (or pay-a-subset) method is either equal or even superior to the pay-all method in the majority of cases.

The treatments B-LOSER and B-WINNER are identical to BASELINE with the only difference that, respectively, the worst performer (loser) or the top performer (winner) in the ranking of each group was publicly announced after the last period of the investment game. This procedure was common knowledge from the beginning of the experiment.

In Treatment RANKING, the participants received the same linear incentives as in BASELINE, but after each period we showed them an anonymous league table, detailing all group members' current wealth levels, associated rank $(R A N K \in\{1,2, \ldots, 6\})$, and their own position in the ranking. This ranking was not incentivized, and there was no public disclosure of the ranking in the end. Hence, we apply a very mild form of social comparison in this treatment. Data of treatments BASELINE and RANKING are taken from the experiments in Kirchler et al. (2018)..$^{11}$

Treatments R-LOSER and R-WINNER are identical to Treatment RANKING, except for the announcement of the loser or the winner, respectively, according to the ranking in each group. The treatments with the public announcement of the loser, or respectively the winner, are designed to investigate the effect of reputational motives beyond intrinsic rank incentives.

After the investment game, in a second part of the experiment, we administered two additional experimental tasks, one of which was paid out randomly, and some survey questions. Please see the online appendix for the instructions of all experimental tasks. Part 2 of the instructions were handed out after all participants had completed Part 1. In the first task we measured risk-attitudes in a standard choice list setting (Bruhin et al., 2010; Abdellaoui et al., 2011). ${ }^{12}$ We also measured risk attitudes (on a Likert scale from 1 to 7 ) with a survey question from the German Socio-Economic Panel (SOEP; Dohmen et al., 2011). The participants answered the question: "How do you see yourself: Are you willing to take risks or try to avoid risks?" The answers were provided on a Likert scale from 1 (not at all willing to take risks) to 7 (very willing to take risks). In the second task, we measured loss aversion using the procedure of Gächter et al. (2010). ${ }^{13}$ The participants earned 18 euro as a show-up fee for participating in the experiment, which covered the potential maximum loss in the loss aversion task. In the

\footnotetext{
${ }^{11}$ In Kirchler et al. (2018) the treatments BASELINE and RANKING are referred to as TBASE and TRANK, respectively.

${ }^{12}$ The participants could choose between a risky option, paying either 0 or 8 euro with equal probability, or a safe payment, which ranged between 1 and 7 euro in steps of 1 euro.

${ }^{13}$ In the task measuring loss aversion, the participants had to decide whether to play a particular lottery or not. If they decided to play the lottery, they either received, with equal probability, 15 euro or incured a loss of X. The loss $X$ varied from 1 to 6 euro in steps of 1 euro. If the participants decided not to play a particular lottery, they received a payout of zero.
} 
survey, we measured the participants' attitudes toward social comparison with three questions on social status, financial success, and relative performance, taken from Cohn et al. (2014). Furthermore, we measured CRT scores (Cognitive Reflection Test, Frederick, 2005) with slightly modified questions (see appendix). ${ }^{14}$ Questions on demographics concluded the experiment.

\subsection{Hypotheses}

We can now use the treatments defined above to operationalize the propositions from the model. Proposition 1 allows us to formulate hypotheses regarding portfolio choice in different treatments in which investors are informed about their rank and/or the winner or loser is publicly announced:

Hypothesis 1 Risk-taking is higher in treatments where investors are informed about their rank (RANKING), compared to the baseline treatment (BASELINE).

Hypothesis 2 If investors are not informed about their rank, risk-taking is higher in treatments where the winner or the loser is announced (B-LOSER and B-WINNER), compared to the baseline treatment (BASELINE).

Hypothesis 3 In treatments where investors are informed about their rank and where the winner or the loser is announced (R-LOSER and R-WINNER), risk-taking is higher compared to the treatment without announcement (RANKING).

Moreover, based on Proposition 2, we can formulate hypotheses with respect to the portfolio choice of highly ranked investors in comparison to underperformers.

Hypothesis 4 In treatments where investors are informed about their rank (RANKING), the risktaking of highly ranked investors is lower compared to risk-taking of underperformers.

Hypothesis 5 In treatments where investors are informed about their rank and where the winner or the loser is announced (R-LOSER and R-WINNER), the risk-taking of highly ranked investors is lower compared to risk-taking of underperformers.

\subsection{Implementation}

To test our hypotheses we recruited 864 student subjects for Experiment STUD, i.e., 144 subjects for each treatment. We administered the experiment to bachelor and master students from various disciplines at the University of Innsbruck (Austria) at the Innsbruck EconLab.

\footnotetext{
${ }^{14}$ We also elicited the 10-item Big-5 personality traits according to Rammstedt and John (2007) and socially undesirable personality traits, such as narcissism, psychopathy, and machiavellianism (i.e., Dark Triad), using the 12-item test of Jonason and Webster (2010). The questions asked in the survey were programmed in a separate $\mathrm{z}$-Tree file, which will be provided upon request.
} 
We recruited $75.7 \%$ male students to stay as close as possible to the gender ratio of the professionals in Experiment PROF (see below). The average age was 23.2 years, and $47.7 \%$ were students with a major in economics or management. The students received an average payout of 17 euro for both parts of Experiment STUD with a maximum payout of 161 euro and an average duration of 45 minutes per session. We paid out subjects privately, in cash, after the experiment. We programmed and conducted all experiments (STUD and PROF) using the same source code, programmed in z-Tree (Fischbacher, 2007). Student subjects were recruited via hroot (Bock et al., 2014).

For Experiment PROF we recruited 330 professionals from major financial institutions in several OECD countries. All professionals that participated in our experiments were regularly confronted with competitive rankings, bonus incentives, and investment decisions-i.e., professionals from private banking, trading, investment banking, portfolio management, fund management, and wealth management. ${ }^{15}$ In Experiment PROF, $87.3 \%$ of the participants were male, their average age was 36.8 years, and they had been working in the finance industry for 12.6 years on average.

In all experiments with professionals, we booked a conference room on location or in close proximity (for several organizations to participate simultaneously), set up our mobile laboratory, and invited professionals to show up. Our mobile laboratory is virtually identical to the Innsbruck EconLab at the University of Innsbruck, where we ran the experiment with students (see pictures in the appendix). The mobile lab consists of laptops and partition walls on all sides for each participant, allowing for conditions similar to those in regular experimental laboratories. We mainly recruited members of professional associations/societies, ensuring that most sessions were populated with professionals from different institutions. In this way, we achieved high comparability with the student sample, as most professionals did not know, or barely knew, each other. In total, 78, 102, 66, and 84 professionals participated in treatments BASELINE, RANKING, R-LOSER, and R-WINNER, respectively. Because of a limited number of professionals we refrained from running treatments R-LOSER and R-WINNER in Experiment PROF and rather focused on a sufficiently large sample in the four other treatments.

All specifications were identical to the experiment with students except for the stake size. Similar to other studies (List and Haigh, 2005; Alevy et al., 2007; Cohn et al., 2014; Kirchler et al., 2018), we scaled up the students' payoffs with a multiplier of three for professionals in all parts of the experiment. The professionals received an average payout of 48 euro for both parts of Experiment PROF, with a maximum payout of 286 euro and an average duration of 45 minutes per session. For participants who received money in the investment game, the average payout was 112 euro for a task of 20 minutes, ensuring salient incentives for professionals. ${ }^{16}$ The

\footnotetext{
${ }^{15}$ We signed non-disclosure agreements (NDA) regarding the identity of the participating financial institutions.

${ }^{16}$ In the questionnaire, the professionals reported an average annual gross salary of 76,548 euro. Accordingly,
} 
professionals received the payout in sealed envelopes and in cash directly after the experiment.

\section{Results}

To test Hypotheses $\mathrm{H} 1$ to H5, we run random effects panel regressions with AR(1) disturbance. ${ }^{17}$ In all specifications, the percentage that subjects invested in the risky asset (RISK) is the dependent variable. As control variables, we include $R_{p, t-1}$, which measures the log-return of subject $i$ 's portfolio since the start of the experiment, and $R_{m, t-1}$, which records the preceding period's asset return. With treatment dummies we test for differences between treatments, as defined in the hypotheses. With $R A N K_{t-1}$, which denotes subject $i$ 's rank at the end of the preceding period, we analyze the effect of relative performance on risk-taking. The results are reported in Tables 2 (STUD) and 3 (PROF).

Result 1 (H1): Average risk-taking does not differ between treatments where investors are informed about their rank (RANKING) and the baseline treatment (BASELINE). This holds for both experiments, STUD and PROF.

The coefficients of the intercept and of the treatment dummy RANKING in the first column of Tables 2 and 3 show the levels of risk-taking in the two relevant treatments. Risk-taking in Experiment STUD increases from 73.5\% (coefficient of $\alpha$ ) in Treatment BASELINE to 79.4\% in Treatment RANKING (sum of coefficients of $\alpha$ and of dummy RANKING). However, this increase is not statistically significant (at $p<0.05$ ), as shown by the standard errors for the dummy RANKING. In Experiment PROF, the level of risk-taking is generally higher than in Experiment STUD: the corresponding levels of risk-taking by professionals are $97.0 \%$ and $104.4 \%$ in Treatments BASELINE and RANKING, respectively. Again, this increase is not statistically significant. This result is in line with Kirchler et al. (2018). We include it for the sake of completeness and as a comparison for our analyses of status concerns in the following hypotheses.

Result 2 (H2): In Experiment STUD, average risk-taking is higher in treatments in which the winner or the loser is announced (B-WINNER and B-LOSER), compared to the baseline treatment (BASELINE).

the average (maximum) hourly payoff from the experiment amounted to roughly 2.9 times (18 times) the average professional's hourly wage after taxes. For this calculation, we assumed a working time of 45 hours/week for 47 weeks/year and $40 \%$ taxes to calculate an hourly net wage (22 euro). In our experiment, the participants' average (maximum) hourly payment was 64 (381) euro (48*60/45 and 286*60/45), resulting in $295 \%(1,756 \%$ ) of their salary. Haigh and List (2005) report that their average traders' payment for a 25-minute task was 40 U.S. dollars, which translates to an hourly payment of 96 U.S. dollars. Given an exchange rate of about 1.32 at the time of the study, the payment in Haigh and List (2005) is equivalent to an average hourly wage of 73 euro. Note that monetary incentives in experiments with a representative sample of the general population are less accurate because of the high heterogeneity in the participants' salaries. In our case, the hourly payout of nearly three times the average applies to a sample with a more homogeneous salary distribution.

${ }^{17}$ See the appendix for a randomization check. It turns out that the only variables that are significantly different across treatments are age and loss aversion. As a robustness check, we add these two control variables in the regression models, leading to qualitatively identical results. 
Recall that we did not run Treatments B-WINNER and B-LOSER in Experiment PROF. We therefore test Hypothesis 2 with Experiment STUD only. As reported in Columns 2 and 3 of Table 2, average risk-taking in treatments accounting for reputational motives is significantly higher compared to the baseline treatment in Experiment STUD. When pooling Treatments B-WINNER and B-LOSER with the dummy WIN\&LOS, the effect of reputational motives on risk-taking is significant at a $5 \%$ level. This effect is mainly driven by announcing top performers in Treatment B-WINNER, with a highly significant increase of risk-taking by 18 percentage points (and an average level of risk-taking of $92.1 \%$ ). When the bottom-ranked subjects are announced in Treatment B-LOSER, average risk-taking is $82.9 \%$ and not statistically different from the baseline treatment.

Result 3 (H3): In Experiment STUD, average risk-taking is higher when investors are informed about their rank and when the winner or the loser is announced (R-WINNER and R-LOSER), compared to no announcement (RANKING). This effect does not hold in Experiment PROF.

As shown in Columns 4 and 5 of Table 2, even when controlling for intrinsic rank incentives, reputational motives in Treatments R-WINNER and R-LOSER significantly increase average risk-taking compared to Treatment RANKING in Experiment STUD. This effect is, again, mainly driven by the announcement of top performers in Treatment R-WINNER, similar to the above results in support of Hypothesis 2. The aggregate effect of both treatments (dummy WIN\&LOS), reported in Column 4 , is significant at a $0.1 \%$ level. For professionals, we find no differences in average risk-taking between Treatments R-WINNER, R-LOSER, and RANKING (see Columns 2 and 3 of Table 3). This striking difference in behavior compared to the student sample may be due to the relatively high risk-taking of underperforming professionals in RANKING. We will return to this finding when testing Hypothesis H4.

Result 4 (H4): In Experiment PROF, in treatments where investors are informed about their rank (RANKING), the risk-taking of highly ranked investors is lower compared to that of underperformers. This effect does not apply to Experiment STUD.

Column 4 of Table 3 reports that the coefficient for the variable $R A N K_{t-1}$ is positive and significant. This indicates that underperforming professionals increase risk-taking markedly compared to outperformers. With a coefficient of 5.1, the effect is significant on a $1 \%$ level, translating into a difference in risk-taking of more than 30 percentage points between rank 6 and rank 1. In contrast, students do not react to anonymous rankings, leaving the coefficient of variable $R A N K_{t-1}$ insignificant (see Column 6 of Table 2). This difference in rank effects between the two subject pools has been shown in Kirchler et al. (2018) but is important to recall, as it may help to understand Result 3 above. Specifically, the fact that intrinsic rank effects strongly increase the risk-taking of underperforming professionals but not of students (Result 4) seems to leave room for underperforming students to react to reputational motives (R-WINNER and R-LOSER). In contrast, professionals (Result 3) have reached similarly high levels of risk-taking, even without the announcement of winners or losers (in RANKING). 
Table 2: Econometric Estimation of Experiment STUD

Random effects panel regressions with $\mathrm{AR}(1)$ disturbance, testing treatment differences of students' percentage invested in the risky asset (RISK). $R_{p, t-1}$ is the log-return of subject $i$ 's portfolio since the start of the experiment, and $R_{m, t-1}$ is the preceding period's asset return. $R A N K_{t-1}$ indicates subject $i$ 's rank at the end of the preceding period. In Columns H1 to H2(ii), Treatment BASELINE, in which the students invested without information on their rank, serves as the reference group. Treatment RANKING was identical except for the display of an anonymous and non-incentivized ranking after each period and serves as a reference group for H3(i) and H3(ii). Treatments B-LOSER (B-WINNER) and R-LOSER (R-WINNER) were identical to BASELINE and RANKING except that the lowest (top) performer in a group of six was publicly announced after the final period. The dummy variable WIN\&LOS indicates whether observations are from treatments B-LOSER or B-WINNER (if the reference treatment is BASELINE) or from R-LOSER or R-WINNER (if the reference treatment is RANKING). Column H4 displays Treatment RANKING and H5 treatments R-LOSER and R-WINNER. Standard errors are provided in parentheses. ${ }^{* * *}$, $*$, and ${ }^{*}$ represent significance at the $0.1 \%, 1 \%$, and $5 \%$ levels, respectively.

\begin{tabular}{|c|c|c|c|c|c|c|c|}
\hline \multirow[b]{2}{*}{ Dep. var: RISK } & \multicolumn{7}{|c|}{ Hypotheses } \\
\hline & $\mathrm{H} 1$ & $\mathrm{H} 2 \mathrm{i}$ & $\mathrm{H} 2 \mathrm{ii}$ & $\mathrm{H} 3 \mathrm{i}$ & H3ii & $\mathrm{H} 4$ & $\mathrm{H} 5$ \\
\hline$R_{p, t-1}$ & $\begin{array}{c}-0.386^{* * *} \\
(0.047)\end{array}$ & $\begin{array}{c}-0.360^{* * * *} \\
(0.036)\end{array}$ & $\begin{array}{c}-0.361^{* * *} \\
(0.036)\end{array}$ & $\begin{array}{c}-0.206^{* * *} \\
(0.035)\end{array}$ & $\begin{array}{c}-0.206^{* * * *} \\
(0.035)\end{array}$ & $\begin{array}{c}-0.295^{* * *} \\
(0.076)\end{array}$ & $\begin{array}{l}-0.103^{*} \\
(0.043)\end{array}$ \\
\hline$R_{m, t-1}$ & $\begin{array}{l}-0.041 \\
(0.060)\end{array}$ & $\begin{array}{c}-0.225^{* * *} \\
(0.048)\end{array}$ & $\begin{array}{c}-0.225^{* * *} \\
(0.048)\end{array}$ & $\begin{array}{l}-0.114^{*} \\
(0.055)\end{array}$ & $\begin{array}{l}-0.114^{*} \\
(0.055)\end{array}$ & $\begin{array}{l}-0.090 \\
(0.094)\end{array}$ & $\begin{array}{l}-0.175^{*} \\
(0.068)\end{array}$ \\
\hline RANKING & $\begin{array}{c}5.854 \\
(6.089)\end{array}$ & & & & & & \\
\hline WIN\&LOS & & $\begin{array}{l}13.391^{*} \\
(5.252)\end{array}$ & & $\begin{array}{c}19.001^{* * *} \\
(5.143)\end{array}$ & & & \\
\hline B-LOSER & & & $\begin{array}{c}8.809 \\
(6.046)\end{array}$ & & & & \\
\hline B-WINNER & & & $\begin{array}{c}17.979 * * \\
(6.048)\end{array}$ & & & & \\
\hline R-LOSER & & & & & $\begin{array}{l}12.079^{*} \\
(5.902)\end{array}$ & & \\
\hline R-WINNER & & & & & $\begin{array}{c}25.924^{* * *} \\
(5.903)\end{array}$ & & $\begin{array}{l}14.018^{*} \\
(5.730)\end{array}$ \\
\hline$R_{A N K_{t-1}}$ & & & & & & $\begin{array}{c}1.630 \\
(1.343)\end{array}$ & $\begin{array}{c}4.354^{* * *} \\
(0.935)\end{array}$ \\
\hline$\alpha$ & $\begin{array}{c}73.528^{* * * *} \\
(4.301)\end{array}$ & $\begin{array}{c}74.093^{* * *} \\
(4.284)\end{array}$ & $\begin{array}{c}74.093^{* * *} \\
(4.273)\end{array}$ & $\begin{array}{c}78.232^{* * * *} \\
(4.208)\end{array}$ & $\begin{array}{c}78.228^{* * * *} \\
(4.183)\end{array}$ & $\begin{array}{c}73.192^{* * *} \\
(6.569) \\
\end{array}$ & $\begin{array}{c}74.492^{* * *} \\
(5.264)\end{array}$ \\
\hline $\mathrm{N}$ & 2016 & 3024 & 3024 & 3024 & 3024 & 1008 & 2016 \\
\hline $\mathrm{R}^{2}$ & 0.072 & 0.073 & 0.077 & 0.042 & 0.049 & 0.049 & 0.035 \\
\hline $\mathrm{Chi}^{2}$ & 83.290 & 190.457 & 192.886 & 72.674 & 78.479 & 32.607 & 61.019 \\
\hline $\mathrm{p}$-value & 0.000 & 0.000 & 0.000 & 0.000 & 0.000 & 0.000 & 0.000 \\
\hline Treatments & $\begin{array}{l}\text { BASELINE } \\
\text { RANKING }\end{array}$ & $\begin{array}{l}\text { BASELINE } \\
\text { B-LOSER } \\
\text { B-WINNER }\end{array}$ & $\begin{array}{l}\text { BASELINE } \\
\text { B-LOSER } \\
\text { B-WINNER }\end{array}$ & $\begin{array}{l}\text { RANKING } \\
\text { R-LOSER } \\
\text { R-WINNER }\end{array}$ & $\begin{array}{l}\text { RANKING } \\
\text { R-LOSER } \\
\text { R-WINNER }\end{array}$ & RANKING & $\begin{array}{l}\text { R-LOSER } \\
\text { R-WINNER }\end{array}$ \\
\hline Reference & BASELINE & BASELINE & BASELINE & RANKING & RANKING & none & R-LOSER \\
\hline
\end{tabular}




\section{Table 3: Econometric Estimation of Experiment PROF}

Random effects panel regressions with $\mathrm{AR}(1)$ disturbance, testing treatment differences of professionals' percentage invested in the risky asset (RISK). $R_{p, t-1}$ is the log-return of subject $i$ 's portfolio since the start of the experiment, and $R_{m, t-1}$ is the preceding period's asset return. $R A N K_{t-1}$ indicates subject $i$ 's rank at the end of the preceding period. In Column H1, Treatment BASELINE, in which the professionals decided without information on their rank, serves as the reference group. Treatment RANKING was identical except for the display of an anonymous and non-incentivized ranking after each period and serves as a reference group for H3(i) and H3(ii). Treatments B-LOSER (B-WINNER) and R-LOSER (R-WINNER) were identical to BASELINE and RANKING except that the lowest (top) performer in a group of six was publicly announced after the final period. The dummy variable WIN\&LOS indicates whether observations are from treatments R-LOSER or R-WINNER (if the reference treatment is RANKING). Column H4 displays Treatment RANKING and H5 Treatments R-LOSER and R-WINNER. Standard errors are provided in parentheses. ${ }^{* * *},{ }^{* *}$, and ${ }^{*}$ represent significance at the $0.1 \%, 1 \%$, and $5 \%$ levels, respectively.

\begin{tabular}{|c|c|c|c|c|c|}
\hline \multirow[b]{2}{*}{ Dep. var: RISK } & \multicolumn{5}{|c|}{ Hypotheses } \\
\hline & $\mathrm{H} 1$ & $\mathrm{H} 3 \mathrm{i}$ & H3ii & $\mathrm{H} 4$ & H5 \\
\hline$R_{p, t-1}$ & $\begin{array}{c}-0.435^{* * *} \\
(0.057)\end{array}$ & $\begin{array}{c}-0.493^{* * *} \\
(0.056)\end{array}$ & $\begin{array}{c}-0.494^{* * *} \\
(0.056)\end{array}$ & $\begin{array}{c}-0.384^{* * *} \\
(0.092)\end{array}$ & $\begin{array}{c}-0.439^{* * *} \\
(0.077)\end{array}$ \\
\hline$R_{m, t-1}$ & $\begin{array}{l}-0.060 \\
(0.094)\end{array}$ & $\begin{array}{l}-0.133 \\
(0.078)\end{array}$ & $\begin{array}{l}-0.132 \\
(0.078)\end{array}$ & $\begin{array}{l}-0.067 \\
(0.129)\end{array}$ & $\begin{array}{l}-0.245^{*} \\
(0.098)\end{array}$ \\
\hline RANKING & $\begin{array}{c}7.442 \\
(7.520)\end{array}$ & & & & \\
\hline WIN\&LOS & & $\begin{array}{l}-7.016 \\
(6.555)\end{array}$ & & & \\
\hline R-LOSER & & & $\begin{array}{l}-4.209 \\
(8.066)\end{array}$ & & \\
\hline R-WINNER & & & $\begin{array}{l}-9.223 \\
(7.524)\end{array}$ & & $\begin{array}{l}-4.787 \\
(8.318)\end{array}$ \\
\hline$R A N K_{t-1}$ & & & & $\begin{array}{l}5.055^{* *} \\
(1.566)\end{array}$ & $\begin{array}{l}4.152^{* *} \\
(1.271)\end{array}$ \\
\hline$\alpha$ & $\begin{array}{c}97.002^{* * *} \\
(5.659)\end{array}$ & $\begin{array}{c}105.619^{* * *} \\
(5.097)\end{array}$ & $\begin{array}{c}105.625^{* * *} \\
(5.095)\end{array}$ & $\begin{array}{c}86.272^{* * *} \\
(7.635)\end{array}$ & $\begin{array}{c}86.611^{* * *} \\
(7.850)\end{array}$ \\
\hline $\mathrm{N}$ & 1260 & 1764 & 1764 & 714 & 1050 \\
\hline $\mathrm{R}^{2}$ & 0.096 & 0.060 & 0.061 & 0.114 & 0.046 \\
\hline $\mathrm{Chi}^{2}$ & 72.702 & 107.609 & 107.924 & 46.438 & 88.045 \\
\hline $\mathrm{p}$-value & 0.000 & 0.000 & 0.000 & 0.000 & 0.000 \\
\hline Treatments & $\begin{array}{l}\text { BASELINE } \\
\text { RANKING }\end{array}$ & $\begin{array}{c}\text { RANKING } \\
\text { R-LOSER } \\
\text { R-WINNER }\end{array}$ & $\begin{array}{c}\text { RANKING } \\
\text { R-LOSER } \\
\text { R-WINNER }\end{array}$ & RANKING & $\begin{array}{c}\text { R-LOSER } \\
\text { R-WINNER }\end{array}$ \\
\hline Reference & BASELINE & RANKING & RANKING & none & R-LOSER \\
\hline
\end{tabular}


Result 5 (H5): In treatments where investors are informed about their rank and the winner or the loser is announced publicly (R-WINNER and R-LOSER), the risk-taking of highly ranked investors is lower compared to that of underperformers.

As outlined in Column 7 of Table 2, the coefficient of the variable $R A N K_{t-1}$ (rank effect) becomes significant for the student sample as soon as reputational motives are added to the ranking in Treatments R-WINNER and R-LOSER. In the professional sample, in contrast, the rank effect remains significant when the rankings are combined with reputational motives (see Column 5 of Table 3). These results indicate that students intrinsically care less about anonymous social comparisons in investment decisions but show similar risk-taking behavior as financial professionals as soon as reputational motives are introduced. Professionals, in contrast, exhibit strong rank-driven behavior, even when only anonymous rankings are displayed, revealing higher levels of intrinsic (self-image) motives to outperform peers in investment decisions (Kirchler et al., 2018).

\section{Conclusion}

In this paper, we presented theoretical mechanisms and experimental evidence regarding how rank incentives impact risk-taking in investment decisions among 864 non-professionals (students) and 330 financial professionals from investment-related areas, such as fund management, trading, private banking, and asset management. In particular, we separate intrinsic (self-image) and reputational (status) motives and investigate their contribution to risk-taking in investment decisions.

We found that average risk-taking among students is higher in treatments in which the winner or the loser is announced publicly, compared to the baseline treatment. The public announcement of winners or losers also increases average risk-taking among students compared to a treatment with anonymous rank information. For professionals, however, we do not observe such effects, which indicates that reputation motives primarily play a role among nonprofessionals. We also find that underperforming investors take more risk than outperformers in treatments where both intrinsic and reputational motives are possible drivers, i.e., where rankings are displayed and the winner or loser is publicly announced. This result holds for both students and professionals. However, while underperforming students do not increase risk-taking without reputational motives, underperforming professionals increase risk-taking primarily in treatments where intrinsic motives play a role.

Reputational motives, as an additional incentive, seem to be of less importance for financial professionals, as the rank-driven behavior of underperformers is already strong when anonymous rankings are in place. This could cautiously be interpreted as professionals showing higher levels of intrinsic (self-image) motives to outperform others compared to nonprofessionals (students) in investment decisions. This may also indicate that professionals' 
intrinsic motivation might include at least some reputational aspects due to identity importing from their decade-long experience in the industry. According to the social identity theory of Akerlof and Kranton (2000), decision-makers have different social identities (e.g., based on gender, ethnicity, or occupation) prescribing how they behave when a certain identity is salient. For instance, Cohn et al. $(2014,2017)$ show that professionals cheat more and take less risks when their professional identity becomes more salient. In our setting, this mechanism would imply that rank-driven behavior can arise through identity transfer from a professional situation containing aspects of extrinsic, intrinsic, and reputational motives to a laboratory situation where rankings are not monetarily incentivized. Following this logic, professionals may react to anonymous rankings in such a comprehensive way that there is little room left for more pronounced behavior when reputational motives are explicitly addressed in the experiment. The absence of students' reaction to anonymous rank incentives, and also their strong reaction to reputational motives (and also to extrinsic, monetary motives, as shown in Kirchler et al. (2018)), provide further support for this notion. Students lack the professional identity of a banker, and hence anonymous rankings cannot trigger identity importing from comparable situations in real life, where bonuses, status, and career prospects are tied to rankings in general.

Of course, this paper can only attempt to shed some light on the complex relationships between extrinsic, intrinsic, and reputational motives on risk-taking and the possible import of professional norms and values into competitive investment decisions. Further research is needed to disentangle these mechanisms and their effects on risk-taking and decision-making in general. 


\section{References}

Abdellaoui, Mohammed, Aurélien Baillon, Laetitia Placido, Peter P. Wakker. 2011. The rich domain of uncertainty: Source functions and their experimental implementation. American Economic Review 101(2) 695-723.

Akerlof, George, Rachel Kranton. 2000. Economics and identity. Quarterly Journal of Economics 115(3) 715-753.

Akerlof, Robert J., Richard T. Holden. 2012. The nature of tournaments. Economic Theory 51(2) 289-313.

Alevy, Jonathan E., Michael S. Haigh, John A. List. 2007. Information cascades: Evidence from a field experiment with financial market professionals. Journal of Finance 62(1) 151-180.

Azmat, Ghazala, Nagore Iriberri. 2010. The importance of relative performance feedback information: Evidence from a natural experiment using high school students. Journal of Public Economics 94(7-8) 435-452.

Balafoutas, Loukas, E. Glenn Dutcher, Florian Lindner, Dmitry Ryvkin. 2017. The optimal allocation of prizes in tournaments of heterogeneous agents. Economic Inquiry 55(1) 461-478.

Bandiera, Oriana, Iwan Barankay, Imran Rasul. 2013. Team incentives: Evidence from a firm level experiment. Journal of the European Economic Association 11(5) 1079-1114.

Barankay, Iwan. 2015. Rank incentives: Evidence from a randomized workplace experiment. Working Paper.

Bebchuk, Lucian, Holger Spamann. 2010. Regulating bankers' pay. Georgetown Law Journal 98(2) 247-287.

Bénabou, Roland, Jean Tirole. 2006. Incentives and Prosocial Behavior. American Economic Review 96(5) 1652-1678.

Bénabou, Roland, Jean Tirole. 2016. Bonus culture: competitive pay, screening, and multitasking. Journal of Political Economy 124(2) 305-370.

Blanes-i-Vidal, Jordi, Mareike Nossol. 2011. Tournaments without prizes: Evidence from personnel records. Management Science 57(10) 1721-1736.

Bock, Olaf, Ingmar Baetge, Andreas Nicklisch. 2014. hroot: Hamburg registration and organization online tool. European Economic Review 71 117-120.

Bradbury, Meike, Thorsten Hens, Stefan Zeisberger. 2015. Improving investment decisions with simulated experience. Review of Finance 19(3) 1019-1052. 
Bruhin, Adrian, Helga Fehr-Duda, Thomas Epper. 2010. Risk and rationality: Uncovering heterogeneity in probability distortion. Econometrica 78(4) 1375-1412.

Charness, Gary, Uri Gneezy, Brianna Halladay. 2016. Experimental methods: pay one or pay all. Journal of Economic Behavior and Organization 131 141-150.

Charness, Gary, David Masclet, Marie Claire Villeval. 2014. The dark side of competition for status. Management Science 60(1) 38-55.

Cohn, Alain, Ernst Fehr, Michel André Maréchal. 2014. Business culture and dishonesty in the banking industry. Nature 516 86-89.

Cohn, Alain, Ernst Fehr, Michel André Maréchal. 2017. Do professional norms in the banking industry favor risk-taking? Review of Financial Studies 30(11) 3801-3823.

Cubitt, Robin P., Chris Starmer, Robert Sugden. 1998. On the validity of the random lottery incentive system. Experimental Economics 1(2) 115-131.

Delfgaauw, Josse, Robert Dur, Joeri Sol, Willem Verbeke. 2013. Tournament incentives in the field: Gender differences in the workplace. Journal of Labor Economics 31(2) 305-326.

Diamond, Douglas W., Raghuram G. Rajan. 2009. The credit crisis: Conjectures about causes and remedies. American Economic Review 99(2) 606-610.

Dohmen, Thomas J., Armin Falk, David Huffman, Juergen Schupp, Uwe Sunde, Gert Wagner. 2011. Individual risk attitudes: Measurement, determinants, and behavioral consequences. Journal of the European Economic Association 9(3) 522-550.

Ehm, Christian, Christine Kaufmann, Martin Weber. 2014. Volatility inadaptability: Investors care about risk, but can't cope with volatility. Review of Finance 18 1387-1423.

Fischbacher, Urs. 2007. z-tree: Zurich toolbox for ready-made economic experiments. Experimental Economics 10(2) 171-178.

Frank, Robert H. 1985. Choosing the right pond: Human behavior and the quest for status. Oxford University Press.

Frederick, Shane. 2005. Cognitive reflection and decision making. Journal of Economic Perspectives 19(4) 25-42.

Gächter, Simon, Eric J. Johnson, Andreas Herrmann. 2010. Individual-level loss aversion in riskless and risky choices. CeDEx Discussion Paper No. 2010-10.

Goetzmann, William N., Jonathan E. Ingersoll, Stephen A. Ross. 2003. High-water marks and hedge fund management contracts. Journal of Finance 58(4) 1685-1718. 
Gürtler, Oliver, Matthias Kräkel. 2010. Optimal tournament contracts for heterogeneous workers. Journal of Economic Behavior \& Organization 75(2) 180-191.

Haigh, Michael S., John A. List. 2005. Do professional traders exhibit myopic loss aversion? An experimental analysis. Journal of Finance 60(1) 523-534.

Heffetz, Ori, Robert H. Frank. 2011. Handbook of Social Economics, vol. 1, chap. Preferences for Status: Evidence and Economic Implications. North-Holland, 69-91.

Hey, John D., Jinkwon Lee. 2005. Do subjects separate (or are they sophisticated)? Experimental Economics 8(3) 233-265.

Huber, Jürgen, Michael Kirchler, Thomas Stöckl. 2016. The influence of investment experience on market prices: Laboratory evidence. Experimental Economics 19(2) 394-411.

Jonason, Peter K., Gregory D. Webster. 2010. The dirty dozen: A concise measure of the dark triad. Psychological Assessment 22(2) 420-432.

Kaufmann, Christine, Martin Weber, Emily Celia Haisley. 2013. The role of experience sampling and graphical displays on one's investment risk appetite. Management Science 59(2) 323-340.

Kirchler, Michael, Florian Lindner, Utz Weitzel. 2018. Rankings and risk-taking in the finance industry. Journal of Finance 73(5) 2271-2302.

Köszegi, Botond. 2006. Ego utility, overconfidence, and task choice. Journal of the European Economic Association 4(4) 673-707.

List, John A., Michael S. Haigh. 2005. A simple test of expected utility theory using professional traders. Proceedings of the National Academy of Science 102(3) 945-948.

Lohrenz, Terry, Kevin McCabe, Colin F. Camerer, Read Montague. 2007. Neural signature of fictive learning signals in a sequential investment task. Proceedings of the National Academy of Science 104(22) 9493-9498.

March, Christoph, Anthony Ziegelmeyer, Ben Greiner, René Cyranek. 2015. Monetary incentives in large-scale experiments: A case study of risk aversion. Working Paper.

Moldovanu, Benny, Aner Sela, Xianwen Shi. 2007. Contests for status. Journal of Political Economy 115(2) 338-363.

Nieken, Petra, Dirk Sliwka. 2010. Risk-taking tournaments - Theory and experimental evidence. Journal of Economic Psychology 31(3) 254-268. 
Rajan, Raghuram G. 2006. Has finance made the world riskier? European Financial Management 12(4) 499-533.

Rammstedt, Beatrice, Oliver P. John. 2007. Measuring personality in one minute or less: A 10-item short version of the big five inventory in english and german. Journal of Research in Personality 41(1) 203-212.

Schram, Arthur, Jordi Brandts, Klarita Gërxhani. 2018. Social-status ranking: a hidden channel to gender inequality under competition. Experimental Economics forthcoming.

Starmer, Chris, Robert Sugden. 1991. Does the random-lottery incentive system elicit true preferences? An experimental investigation. American Economic Review 81(4) 971-978.

Tran, Anh, Richard Zeckhauser. 2012. Rank as an inherent incentive: Evidence from a field experiment. Journal of Public Economics 96(9-10) 645-650. 


\section{Appendix}

\section{A1 Randomization check}

\section{Table A1: Randomization check}

This table shows Kruskal-Wallis test statistics across treatments within subject pool samples of demographics and other elicited variables - questions about overconfidence, financial risk-taking, loss aversion, risk aversion, CRT score, summary of the three dark triad items (and combined), and the summary of the five Big-5 items.

\begin{tabular}{lcc}
\hline \hline Variable & Students & Fin. Professionals \\
\hline age & $\mathrm{p}<0.005$ & $\mathrm{p}<0.005$ \\
gender & $\mathrm{p}>0.100$ & $\mathrm{p}>0.100$ \\
overconfidence & $\mathrm{p}>0.100$ & $\mathrm{p}>0.100$ \\
risk question & $\mathrm{p}>0.050$ & $\mathrm{p}>0.100$ \\
LA & $\mathrm{p}<0.005$ & $\mathrm{p}<0.050$ \\
RA & $\mathrm{p}>0.100$ & $\mathrm{p}>0.100$ \\
CRT & $\mathrm{p}>0.100$ & $\mathrm{p}>0.100$ \\
Dark Triad & $\mathrm{p}>0.100$ & $\mathrm{p}>0.050$ \\
Big 5 & $\mathrm{p}>0.100$ & $\mathrm{p}>0.100$ \\
\hline \hline
\end{tabular}




\section{Table A2: Econometric Estimation of Experiment STUD}

Random effects panel regressions with $\mathrm{AR}(1)$ disturbance, testing treatment differences of students' percentage invested in the risky asset (RISK). $R_{p, t-1}$ is the log-return of subject $i$ 's portfolio since the start of the experiment, and $R_{m, t-1}$ is the preceding period's asset return. $R A N K_{t-1}$ indicates subject $i$ 's rank at the end of the preceding period. In Columns $\mathrm{H} 1$ to H2(ii), Treatment BASELINE, in which the students invested without information on their rank, serves as the reference group. Treatment RANKING was identical except for the display of an anonymous and non-incentivized ranking after each period and serves as a reference group for H3(i) and H3(ii). Treatments B-LOSER (B-WINNER) and R-LOSER (R-WINNER) were identical to BASELINE and RANKING except that the lowest (top) performer in a group of six was publicly announced after the final period. The dummy variable WIN\&LOS indicates whether observations are from treatments B-LOSER or B-WINNER (if the reference treatment is BASELINE) or from R-LOSER or R-WINNER (if the reference treatment is RANKING). Column H4 displays Treatment RANKING and H5 treatments R-LOSER and R-WINNER. Standard errors are provided in parentheses. ${ }^{* * *},{ }^{* *}$, and ${ }^{*}$ represent significance at the $0.1 \%, 1 \%$, and $5 \%$ levels, respectively.

\begin{tabular}{|c|c|c|c|c|c|c|c|}
\hline \multirow[b]{2}{*}{ Dep. var: RISK } & \multicolumn{7}{|c|}{ Hypotheses } \\
\hline & $\mathrm{H} 1$ & $\mathrm{H} 2 \mathrm{i}$ & $\mathrm{H} 2 \mathrm{ii}$ & H3i & H3ii & $\mathrm{H} 4$ & H5 \\
\hline$R_{p, t-1}$ & $\begin{array}{c}-0.385^{* * *} \\
(0.046)\end{array}$ & $\begin{array}{c}-0.365^{* * *} \\
(0.035)\end{array}$ & $\begin{array}{c}-0.366^{* * *} \\
(0.035)\end{array}$ & $\begin{array}{c}-0.213^{* * * *} \\
(0.035)\end{array}$ & $\begin{array}{c}-0.213^{* * *} \\
(0.035)\end{array}$ & $\begin{array}{c}-0.293^{* * *} \\
(0.075)\end{array}$ & $\begin{array}{c}-0.115^{* *} \\
(0.043)\end{array}$ \\
\hline$R_{m, t-1}$ & $\begin{array}{l}-0.043 \\
(0.060)\end{array}$ & $\begin{array}{c}-0.223^{* * * *} \\
(0.048)\end{array}$ & $\begin{array}{c}-0.223^{* * * *} \\
(0.048)\end{array}$ & $\begin{array}{l}-0.114^{*} \\
(0.055)\end{array}$ & $\begin{array}{l}-0.114^{*} \\
(0.055)\end{array}$ & $\begin{array}{l}-0.092 \\
(0.094)\end{array}$ & $\begin{array}{c}-0.175^{* *} \\
(0.068)\end{array}$ \\
\hline RANKING & $\begin{array}{c}8.755 \\
(5.769)\end{array}$ & & & & & & \\
\hline WIN\&LOS & & $\begin{array}{c}12.853^{* *} \\
(4.984)\end{array}$ & & $\begin{array}{c}16.108^{* *} \\
(5.098)\end{array}$ & & & \\
\hline B-LOSER & & & $\begin{array}{c}8.745 \\
(5.702)\end{array}$ & & & & \\
\hline B-WINNER & & & $\begin{array}{c}17.050^{* *} \\
(5.732)\end{array}$ & & & & \\
\hline R-LOSER & & & & & $\begin{array}{c}8.674 \\
(5.831)\end{array}$ & & \\
\hline R-WINNER & & & & & $\begin{array}{c}23.315^{* * *} \\
(5.788)\end{array}$ & & $\begin{array}{c}15.030^{* *} \\
(5.530)\end{array}$ \\
\hline$R A N K_{t-1}$ & & & & & & $\begin{array}{c}1.518 \\
(1.339)\end{array}$ & $\begin{array}{c}4.228^{* * *} \\
(0.931)\end{array}$ \\
\hline$\alpha$ & $\begin{array}{c}-17.402 \\
(19.936) \\
\end{array}$ & $\begin{array}{c}-6.435 \\
(20.055) \\
\end{array}$ & $\begin{array}{c}-6.914 \\
(20.011) \\
\end{array}$ & $\begin{array}{c}23.190 \\
(17.293) \\
\end{array}$ & $\begin{array}{c}23.658 \\
(17.168) \\
\end{array}$ & $\begin{array}{c}-3.083 \\
(26.545) \\
\end{array}$ & $\begin{array}{c}40.016 \\
(22.141) \\
\end{array}$ \\
\hline Controls & YES & YES & YES & YES & YES & YES & YES \\
\hline $\mathrm{N}$ & 2016 & 3024 & 3024 & 3024 & 3024 & 1008 & 2016 \\
\hline $\mathrm{R}^{2}$ & 0.142 & 0.151 & 0.154 & 0.080 & 0.087 & 0.092 & 0.074 \\
\hline $\mathrm{Chi}^{2}$ & 125.716 & 259.245 & 261.850 & 104.892 & 112.327 & 44.524 & 83.446 \\
\hline$p$-value & 0.000 & 0.000 & 0.000 & 0.000 & 0.000 & 0.000 & 0.000 \\
\hline
\end{tabular}




\section{Table A3: Econometric Estimation of Experiment PROF}

Random effects panel regressions with $\mathrm{AR}(1)$ disturbance, testing treatment differences of professionals' percentage invested in the risky asset (RISK). $R_{p, t-1}$ is the log-return of subject $i$ 's portfolio since the start of the experiment, and $R_{m, t-1}$ is the preceding period's asset return. $R A N K_{t-1}$ indicates subject $i$ 's rank at the end of the preceding period. In Column H1, Treatment BASELINE, in which the professionals decided without information on their rank, serves as the reference group. Treatment RANKING was identical except for the display of an anonymous and non-incentivized ranking after each period and serves as a reference group for H3(i) and H3(ii). Treatments B-LOSER (B-WINNER) and R-LOSER (R-WINNER) were identical to BASELINE and RANKING except that the lowest (top) performer in a group of six was publicly announced after the final period. The dummy variable WIN\&LOS indicates whether observations are from treatments R-LOSER or R-WINNER (if the reference treatment is RANKING). Column H4 displays Treatment RANKING and H5 Treatments R-LOSER and R-WINNER. Standard errors are provided in parentheses. ${ }^{* * *},{ }^{* *}$, and ${ }^{*}$ represent significance at the $0.1 \%, 1 \%$, and $5 \%$ levels, respectively.

\begin{tabular}{|c|c|c|c|c|c|}
\hline \multirow[b]{2}{*}{ Dep. var: RISK } & \multicolumn{5}{|c|}{ Hypotheses } \\
\hline & H1 & $\mathrm{H} 3 \mathrm{i}$ & H3ii & $\mathrm{H} 4$ & H5 \\
\hline$R_{p, t-1}$ & $\begin{array}{c}-0.435^{* * *} \\
(0.057)\end{array}$ & $\begin{array}{c}-0.500^{* * *} \\
(0.055)\end{array}$ & $\begin{array}{c}-0.501^{* * *} \\
(0.055)\end{array}$ & $\begin{array}{c}-0.404^{* * *} \\
(0.092)\end{array}$ & $\begin{array}{c}-0.445^{\text {*** }} \\
(0.076)\end{array}$ \\
\hline$R_{m, t-1}$ & $\begin{array}{l}-0.060 \\
(0.095)\end{array}$ & $\begin{array}{l}-0.130 \\
(0.078)\end{array}$ & $\begin{array}{l}-0.129 \\
(0.078)\end{array}$ & $\begin{array}{l}-0.064 \\
(0.130)\end{array}$ & $\begin{array}{l}-0.243^{*} \\
(0.098)\end{array}$ \\
\hline RANKING & $\begin{array}{c}9.960 \\
(7.460)\end{array}$ & & & & \\
\hline WIN\&LOS & & $\begin{array}{l}-10.219 \\
(6.396)\end{array}$ & & & \\
\hline R-LOSER & & & $\begin{array}{l}-5.366 \\
(7.736)\end{array}$ & & \\
\hline R-WINNER & & & $\begin{array}{c}-14.316 \\
(7.372)\end{array}$ & & $\begin{array}{l}-9.062 \\
(7.908)\end{array}$ \\
\hline$R A N K_{t-1}$ & & & & $\begin{array}{l}5.114^{* *} \\
(1.558)\end{array}$ & $\begin{array}{l}4.055^{* *} \\
(1.261)\end{array}$ \\
\hline$\alpha$ & $\begin{array}{c}63.816^{* * *} \\
(17.581)\end{array}$ & $\begin{array}{c}79.559^{* * *} \\
(14.360)\end{array}$ & $\begin{array}{c}78.061^{* * *} \\
(14.394)\end{array}$ & $\begin{array}{c}37.635 \\
(24.290)\end{array}$ & $\begin{array}{c}63.704^{* * *} \\
(19.111)\end{array}$ \\
\hline Controls & YES & YES & YES & YES & YES \\
\hline $\mathrm{N}$ & 1260 & 1764 & 1764 & 714 & 1050 \\
\hline $\mathrm{R}^{2}$ & 0.118 & 0.111 & 0.114 & 0.156 & 0.118 \\
\hline $\mathrm{Chi}^{2}$ & 82.422 & 134.094 & 135.445 & 56.992 & 110.064 \\
\hline p-value & 0.000 & 0.000 & 0.000 & 0.000 & 0.000 \\
\hline
\end{tabular}




\section{A2 Pictures of the Experimental Laboratories}

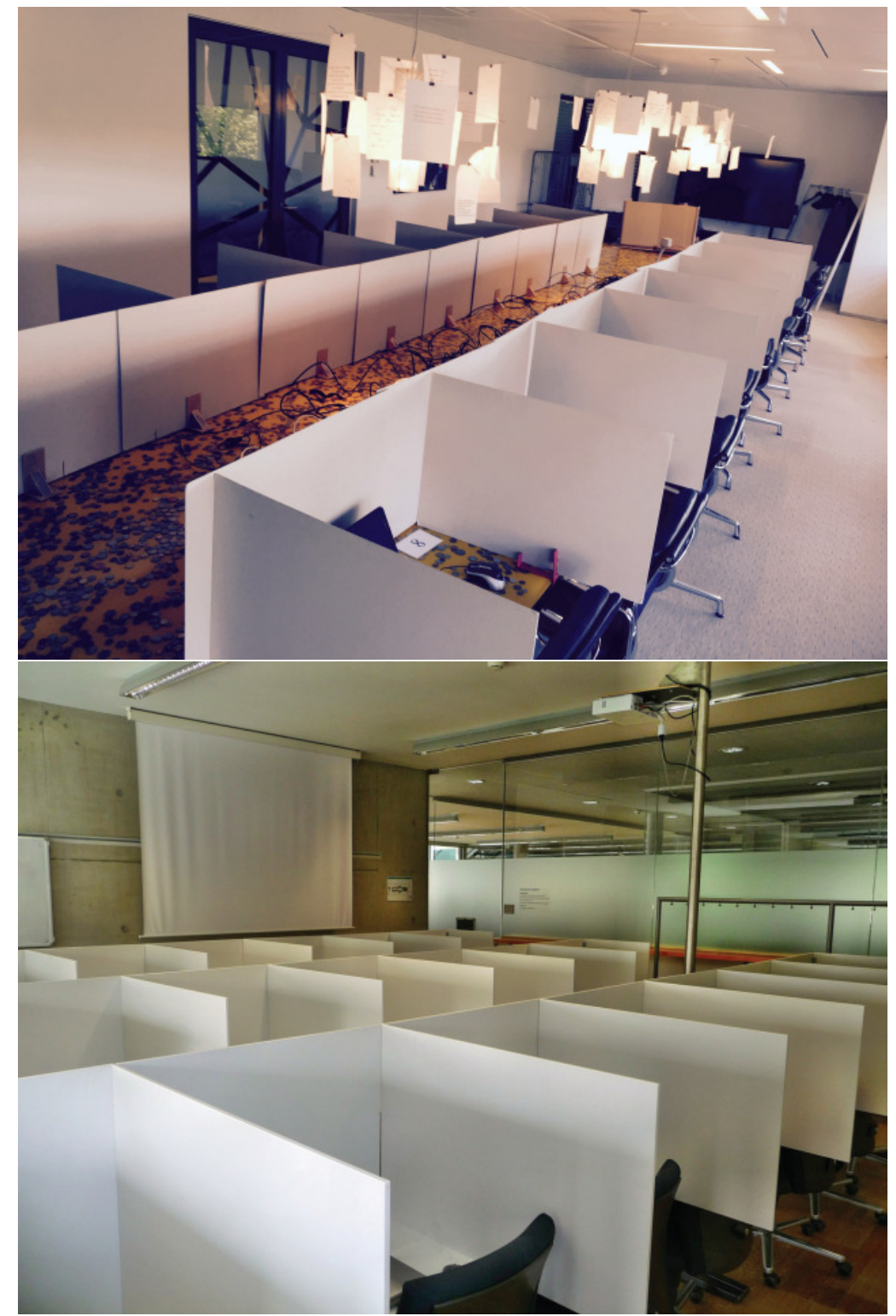

Figure A1: Top: Example of a mobile laboratory in the conference room of a financial institution. Bottom: Innsbruck EconLab. 


\section{A3 Modified CRT Questions}

- An IT company offers you storage space. Every day your volume of data doubles. If it would need 20 days to max out the provided space, how long would it take to max out half of the space?

- A football shoe and a ball cost 110 euro together. The shoe costs 70 euro more than the ball. How much costs the ball?

- 5 machines need 5 minutes to produce 5 keyboards. How long would 80 machines need for 80 keyboards? 


\section{ONLINE APPENDIX \\ Instructions of the Experiment ${ }^{18}$}

\section{Welcome to the experiment and thank you for your participation!}

Please do not talk with the other participants during the experiment from now on.

\section{General Information}

In this experiment we study economic decision-making. The whole experiment consists of two independent parts, where you can earn money independently. For your punctual attendance and participation you will receive a participation fee of 18 euro in addition to the income you can earn in both parts of the experiment. Your entire payment will be paid out to you privately and in cash after the experiment. At the beginning of each part you will receive detailed instructions. If you have questions about the instructions or during the experiment, please raise your hand. One of the experimenters will then come to you and answer your questions privately.

\section{PART 1}

Task

In Part 1 you have to make investment decisions in a financial market. At the beginning of the experiment, you start with a wealth of 90 euro. You have to decide in each of eight periods (half-years), what percentage of your wealth you want to invest at a risk-free rate of $1.5 \%$ and the percentage you wish to invest in a stock index. The development of the stock index reflects the price development of a basket of shares and is based on actual historical data. In the last 20 years, this development is characterized by price fluctuations. In this period, the index earned a half-year return (semi-annual compounding) of $3.6 \%$ and had a standard deviation of the semi-annual price returns of $15.9 \%$.

Here are some examples on the likelihood of various price fluctuations:

In 50 out of 100 cases, the semi-annual return lies between $-7.1 \%$ and $14.3 \%$.

In 90 out of 100 cases, the semi-annual return lies between $-22.6 \%$ and $29.8 \%$.

In 95 out of 100 cases, the semi-annual return lies between $-27.6 \%$ and $34.7 \%$.

At the beginning of the first period, you have to draw 30 times from this distribution (at your laptop) with a mean of $3.6 \%$ and a standard deviation of $15.9 \%$. The draws are independent for each participant. After each draw the last drawn return is indicated on the screen with a yellow box together with the display of return (see Figure A2).

\footnotetext{
${ }^{18}$ Instructions are for Treatment BASELINE for the professional sample. Additional text for Treatments B-WINNER, RANKING, R-WINNER are outlined. The equivalent parts for treatments with public announcement of the worst performer (B-LOSER and R-LOSER) are made analogously and can be provided upon request. Note that instructions for the student sample are identical except that they only received one-third of the monetary incentives.
} 
The previous return draws are shown with red boxes. Every time you click on the "Draw return" button, a new return is drawn from the distribution and displayed on the screen. Together, the draws give you a feeling for the index changes from period to period. The draws are independent of the random draws during the experiment, but the distribution is identical. Below you see an example of the screen (see Figure A2):

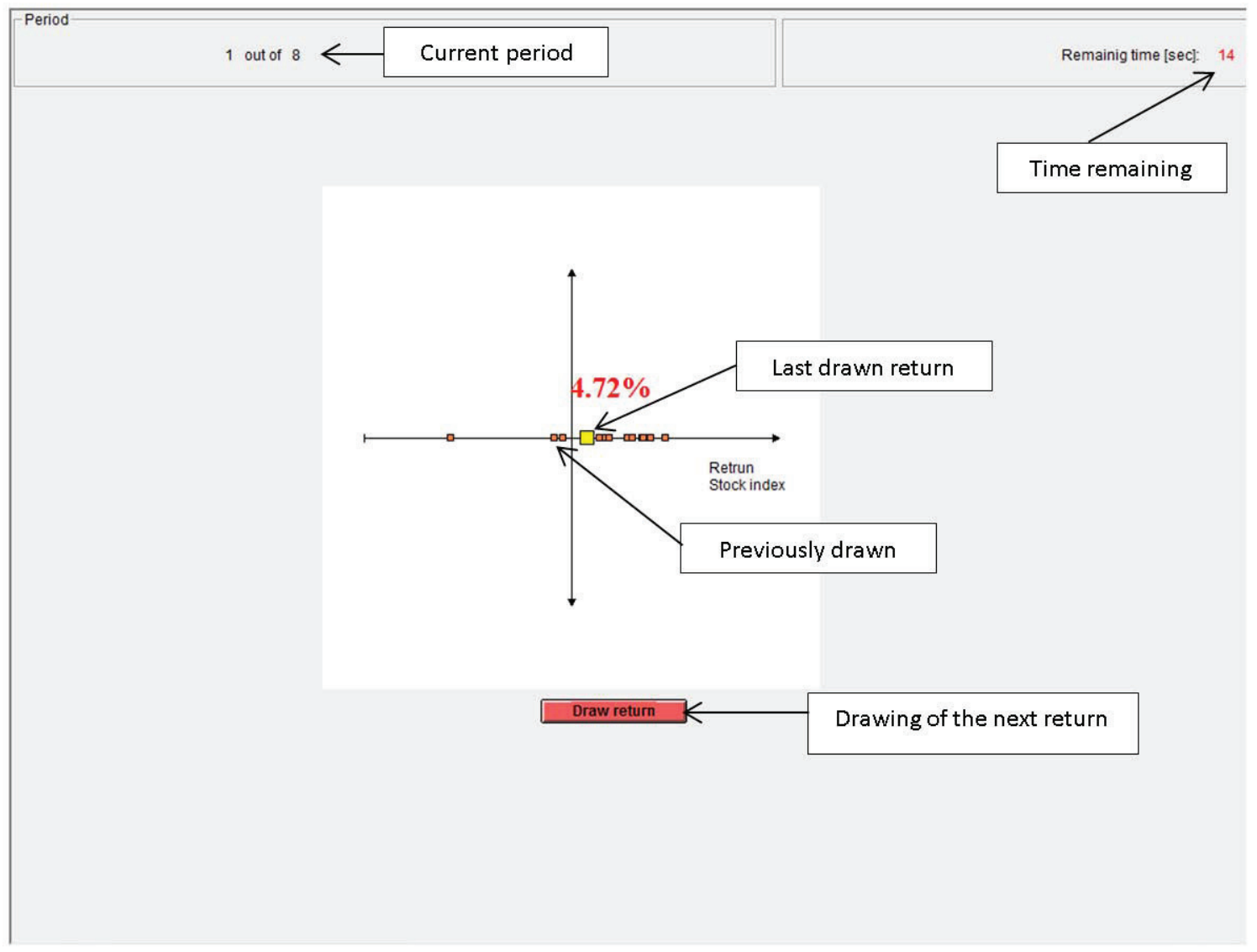

Figure A2: Return screen in Period 1.

In each period you can invest between 0 and $200 \%$ of your current wealth in the stock index. If you invest more than $100 \%$ of your wealth, then the fraction which exceeds $100 \%$ is borrowed at the risk-free rate of $1.5 \%$. If you are investing less than $100 \%$ of your wealth in the stock index, the amount not invested in the stock index is invested at the risk-free rate of $1.5 \%$. You will be selected into a group of 6 participants at the beginning of the experiment and you will remain in the same group for the duration of the experiment (8 periods). At the end of each period the actual return of the stock index is randomly determined from the distribution described above and your wealth will be calculated according to your investment in the stock index and in the risk-free rate. Note that the stock index return is identical for all group members. 


\section{Examples:}

1. Let's assume your wealth is 90 euro and you decide to invest $50 \%$ of it in the stock index. Thus, the remaining $50 \%$ will be invested at the risk-free rate. If the index in this period yields a return of $+10.0 \%$, then your wealth in the next period will be as follows: Profit/loss from the stock index: (50\% Investment * 90 euro) ${ }^{*} 10 \%$ Return $=$ 4.5 euro. Profit from investing in the risk-free interest rate: (50\% Investment * 90 euro $) * 1.5 \%$ Interest $=0.68$ euro. Wealth in the next period: 90 (previous periods wealth) $+4.5+0.68=95.18$ euro.

2. Let's assume your wealth is 90 euro and you decide to invest $150 \%$ of it in the stock index. Thus, you borrow $50 \%$ at the risk-free interest rate. If the index in this period yields a return of $+10.0 \%$, then your wealth in the next period will be as follows: Profit/loss from the stock index: (150\% Investment * 90 euro $) * 10 \%$ Return $=13.5$ euro. Cost of borrowing $50 \%$ at the risk-free rate: $(-50 \%$ Loan $* 90$ euro $) * 1.5 \%$ Interest $=-0.68$ euro. Wealth in the next period: 90 (previous periods wealth) $+13.5-0.68=102.82$ euro.

The decision screen in each period will show your current wealth, the wealth change compared to the previous period, the return of the stock index in the previous period, your invested fraction in the stock index in the previous period, the risk-free rate and your invested fraction in the risk-free asset in the previous period (see Figure A3). The decision screen in all 8 periods looks as follows:

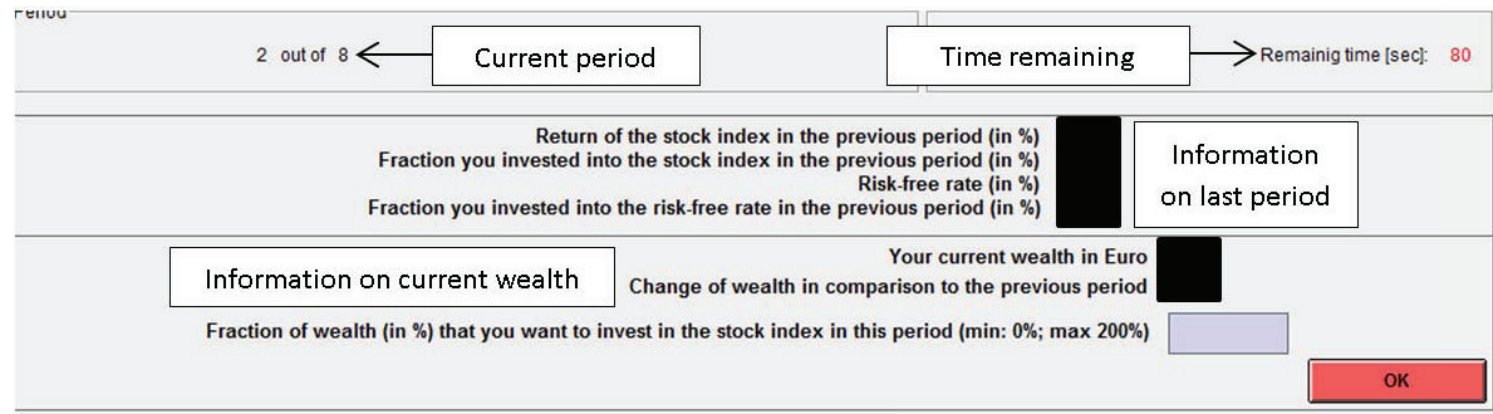

Figure A3: Decision screen in each period (note that this screen is only shown in treatments BASELINE and B-WINNER). 


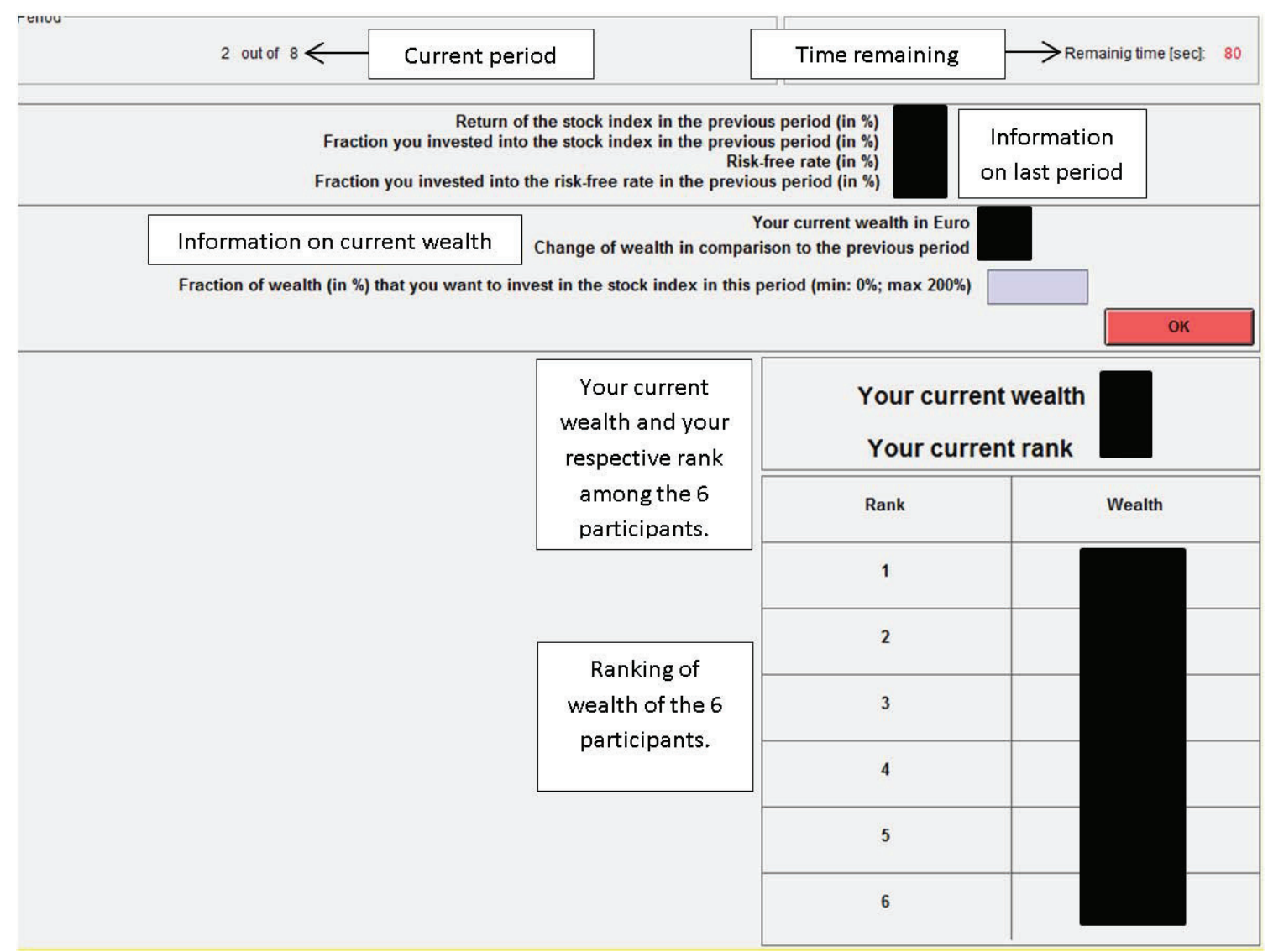

Figure A4: Decision screen in each period (note that this screen is only shown in Treatment RANKING). 


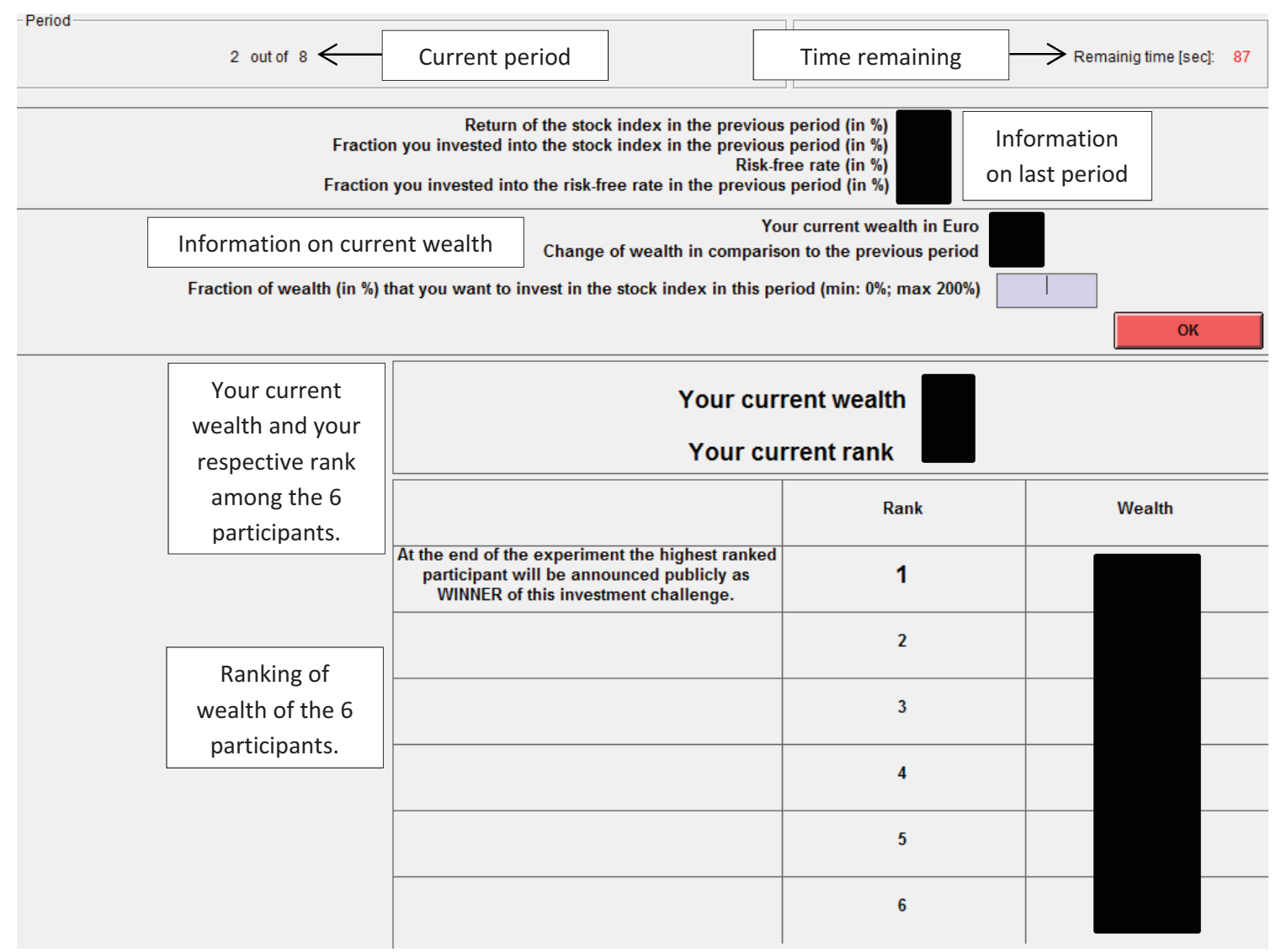

Figure A5: Decision screen in each period (note that this screen is only shown in Treatment R-WINNER). 
[Begin additional text for Treatments RANKING and R-WINNER]

Beginning with Period 2, you will be informed in a league table which rank in your group of 6 you currently have based on the current wealth of the participants. You also get information about the current wealth and rank of the other participants in your group. This table appears for 20 seconds at the beginning of each period (see Figure A6) and is also displayed at the bottom of the decision screen (see Figure A4).

[End additional text for Treatments RANKING and R-WINNER]

[Begin text for Treatment B-WINNER]

Public announcement of the winner in each group

At the end of the experiment (before you receive your payment) the highest ranked participant in each group (of 6 participants) will be announced to all participants in the room as WINNER of this investment challenge.

[End text for Treatment B-WINNER]

[Begin text for Treatment R-WINNER]

\section{Public announcement of the winner in each group}

As you see in figures $A 5$ and A7, the first place is highlighted. The reason is that at the end of the experiment (before you receive your payment) the highest ranked participant in each group (of 6 participants) will be announced to all participants in the room as WINNER of this investment challenge.

[End text for Treatment R-WINNER] 


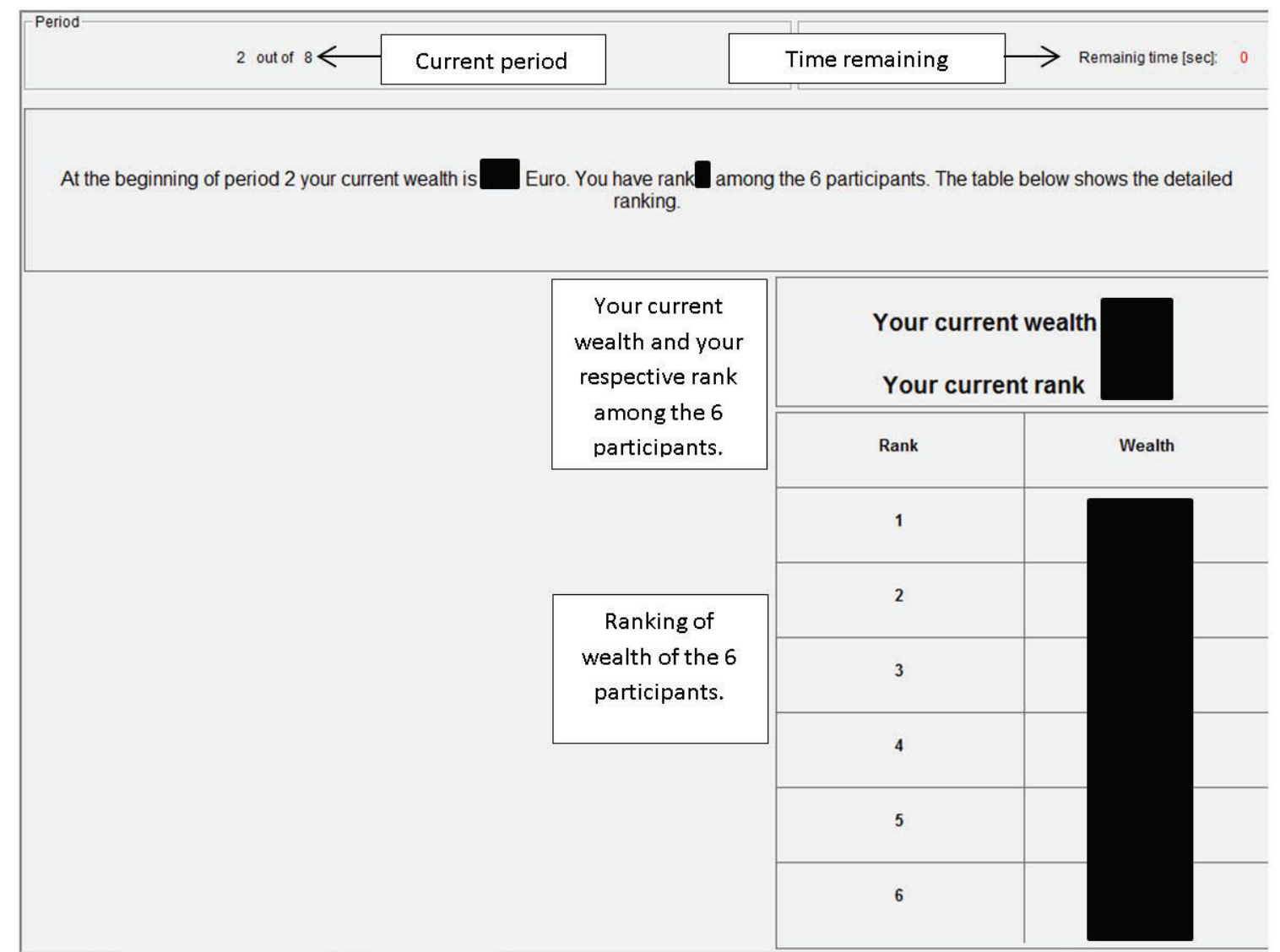

Figure A6: Screen on your ranking and the current wealth of the other participants at the beginning of each period. This table is shown from period 2 onward (note that this screen is only shown in Treatment RANKING).

\section{Payment}

At the end of the experiment, your final wealth (your wealth at the end of period 8) will be paid out to you with a probability of $20 \%$. A random generator determines for each participant separately whether he or she receives the payment. If you are not drawn randomly, you will not receive payment for the first part of the experiment.

[Begin text for Treatments B-WINNER and R-WINNER]

\section{Participation}

This is the end of the instructions of the first part of the experiment. If you do not want to participate in this part, please let us know and then you will participate only in the other parts. In this case we 


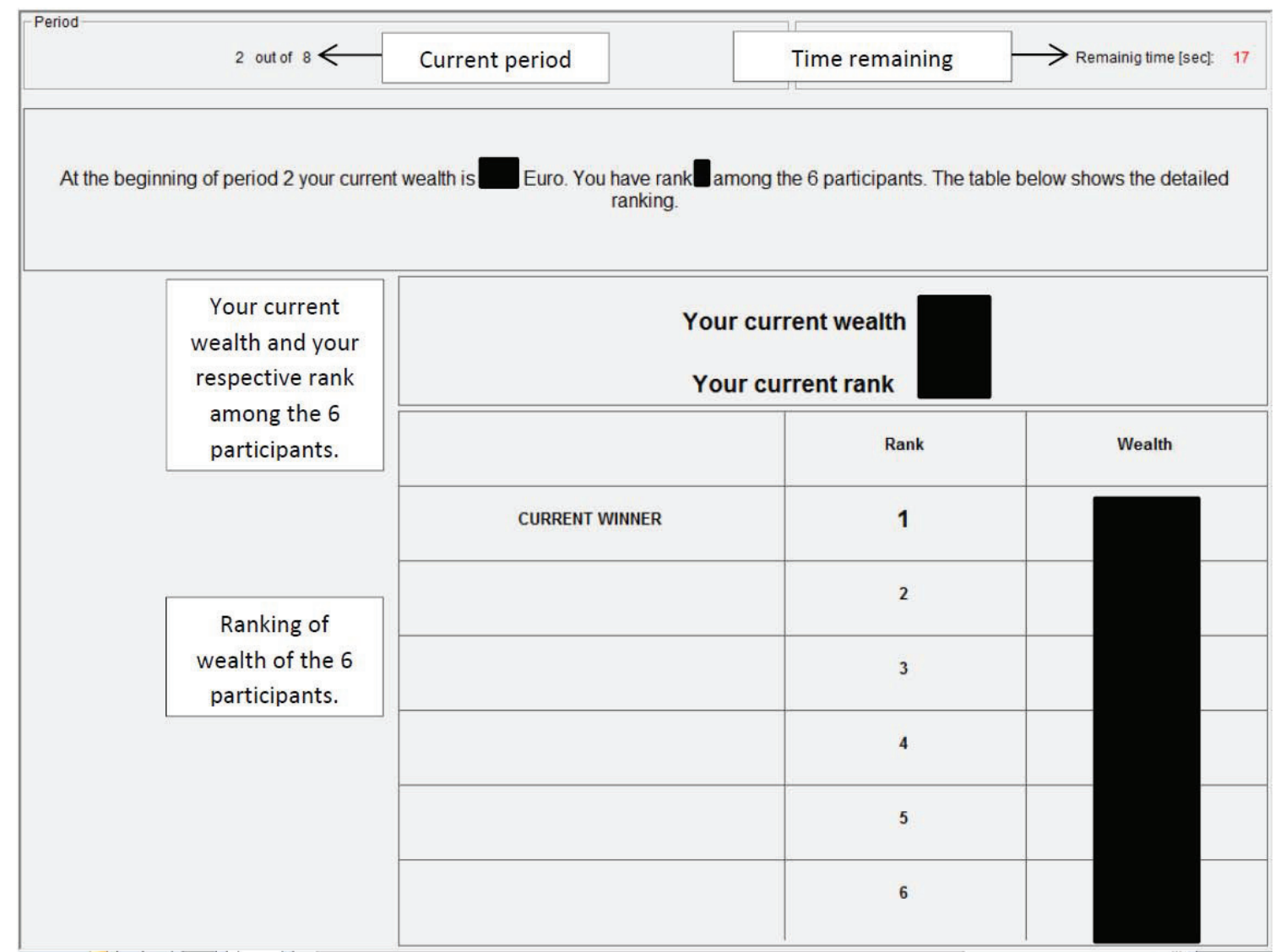

Figure A7: Screen on your ranking and the current wealth of the other participants at the beginning of each period. This table is shown from period 2 onward (note that this screen is only shown in Treatments R-WINNER).

kindly ask you to stay seated during the first 20 minutes without performing a task and wait until Part 2 starts. Note that anonymity for the winner is removed only within the room. Nevertheless, all data and analyses will be done with depersonalized data so that your identity will not be revealed outside of this room.

[End text for Treatments B-WINNER and R-WINNER] 


\section{PART 2}

Below are the instructions for Part 2 of this experiment.

Remember: You get 18 euro for participating in this experiment. In Part 2, you can earn (and lose) in addition to this participation fee. Part 1 and Part 2 are independent in the decisions and in payment.

Part 2 consists of two sections that are played one after the other. For each of the two sections, your potential payment will be calculated individually and independently. At the end of Part 2 one of the two sections will be randomly selected for your payment for Part 2 (for details on payment, see below).

\section{Section 1}

In Section 1, you are asked to make 7 decisions (decision pairs). For each decision pair, you have the choice between Option A and Option B:

OPTION A: A payment with $100 \%$ probability (certainty) is realized. This option is available in all seven decision pairs.

OPTION B: A payment that is risky - either 0 euro with $50 \%$ probability or 24 euro with $50 \%$ probability.

For your payment, ONE out of the 7 decision pairs will be randomly selected and used for payment according to your decision.

\section{Section 2}

In the 6 questions of Section 2 you have to decide whether you want to participate in a lottery where you can win or lose money. If you choose the lottery, the computer flips a coin. If the coin shows heads, you get 15 euro in addition to your participation fee. If the coin shows tails, you lose a certain amount of your participation fee. If you do not choose the lottery, you will receive 0 euro in addition to your participation fees.

For your payment, ONE out of the 6 decision pairs will be randomly selected and used for payment according to your decision.

In Part 2, one of the two sections will be randomly selected and paid out at the end of the experiment; in addition to the participation fee and in addition to the payment of Part 1. Please note: In Part 2, next to playing out a possible lottery, there is a maximum of two random drawings. The first random draw is used to select which section is relevant for your payment. In a second step, one of the decision pairs will be randomly chosen from the relevant section. Your decision (lottery or fixed payment) is then played out to determine your payment.

\section{Questionnaire}


Following Part 2 you will be asked to answer some general questions and provide us with some anonymous demographic details.

Thank you for your participation! 